Research Article

\title{
Novel Crashworthy Device for Pier Protection from Barge Impact
}

\author{
W. Wang (iD) and G. Morgenthal \\ Modeling and Simulation of Structures, Bauhaus University Weimar, Marienstrasse 13, 99423 Weimar, Germany \\ Correspondence should be addressed to W. Wang; dwsjzri@gmail.com
}

Received 22 August 2017; Revised 30 December 2017; Accepted 10 January 2018; Published 2 April 2018

Academic Editor: Chiara Bedon

Copyright (c) 2018 W. Wang and G. Morgenthal. This is an open access article distributed under the Creative Commons Attribution License, which permits unrestricted use, distribution, and reproduction in any medium, provided the original work is properly cited.

\begin{abstract}
Barge impact is a potential hazard for bridge piers located in navigation waterways. Protective structures of different types, for example, dolphin structures, artificial islands, and guiding structures, have been widely used in bridge designs against barge impact. However, such structures often imply high cost and suffer from difficulties in installation as well as maintenance challenges. This paper aims to devise and investigate a new type of crashworthy device which is comprised of vertically supported impact cap connected to the bridge pier using a series of steel beams in a frame-type arrangement. This sacrificial steel structure is designed to form plastic hinges for energy dissipation whilst limiting the force transmitted to the protected pier. The dynamic analysis of the proposed crashworthy device subjected to barge impact is conducted using a simplified impact model previously developed by the authors. The parametric studies in this paper show that the proposed device has a large energy dissipation capacity and that the magnitude of impact force transmitted to the bridge pier can be dramatically reduced. In addition, an optimization model is proposed in this paper to achieve the cost-optimized design of the crashworthy device for a given impact scenario with constraints as per the prescribed design requirements.
\end{abstract}

\section{Introduction}

Bridge piers located in navigation waterways are often threatened by vessel impact due to the increment of vessel transportation volume. It was pointed out by Manen and Frandsen [1] and Larsen [2] previously that at least one major vessel-bridge collision accident of serious consequences occurred each year on average in the past. Barge collisions upon bridge structures were also frequently reported. Such collisions can often lead to catastrophic consequences including human casualties and economic losses; thus substantial investigations regarding the quantification of barge impact loading and dynamic structural responses have been conducted in recent years [3-8].

Different protection measures are being employed to protect bridge piers from vessel impact loading or reduce the damage of bridge piers during impact. As one of these protection measures, independent protective structures such as dolphin structures are frequently used in bridge designs. Such structures were, for example, adopted and installed for long-span bridges such as the Rosario-Victoria Bridge in Argentina [9], the Rhine Bridge in Kehl, Germany [10], and the American Sunshine Bridge [11]. The advantage of such independent protective structures is that they can absorb high impact energy and protect bridge piers from direct contact with the vessels. However, such independent protective structures require high cost and suffer from durability problems and challenges regarding installation and maintenance. In addition, reconstruction of such independent protective structures after being damaged by vessel impact is often expensive, if at all possible. Other protective structures, for example, artificial islands [12] or guiding structures [13], are also frequently used. However, these structures suffer from problems as those mentioned above.

The problems related to the above mentioned protective structures have led to the investigation of bridge protections from impact by strengthening the bridge piers themselves, for example, with carbon fibre-reinforced polymers (CFRPs) $[6,14]$. Such strengthening techniques can improve the pier resistance; that is, the pier undergoes less damage during impact. However, such technique cannot reduce the maximum impact force; therefore, it is effective for pier protection but not for barge protection [6]. In addition, the studies by Sha and Hao [6] indicate that the effectiveness of 

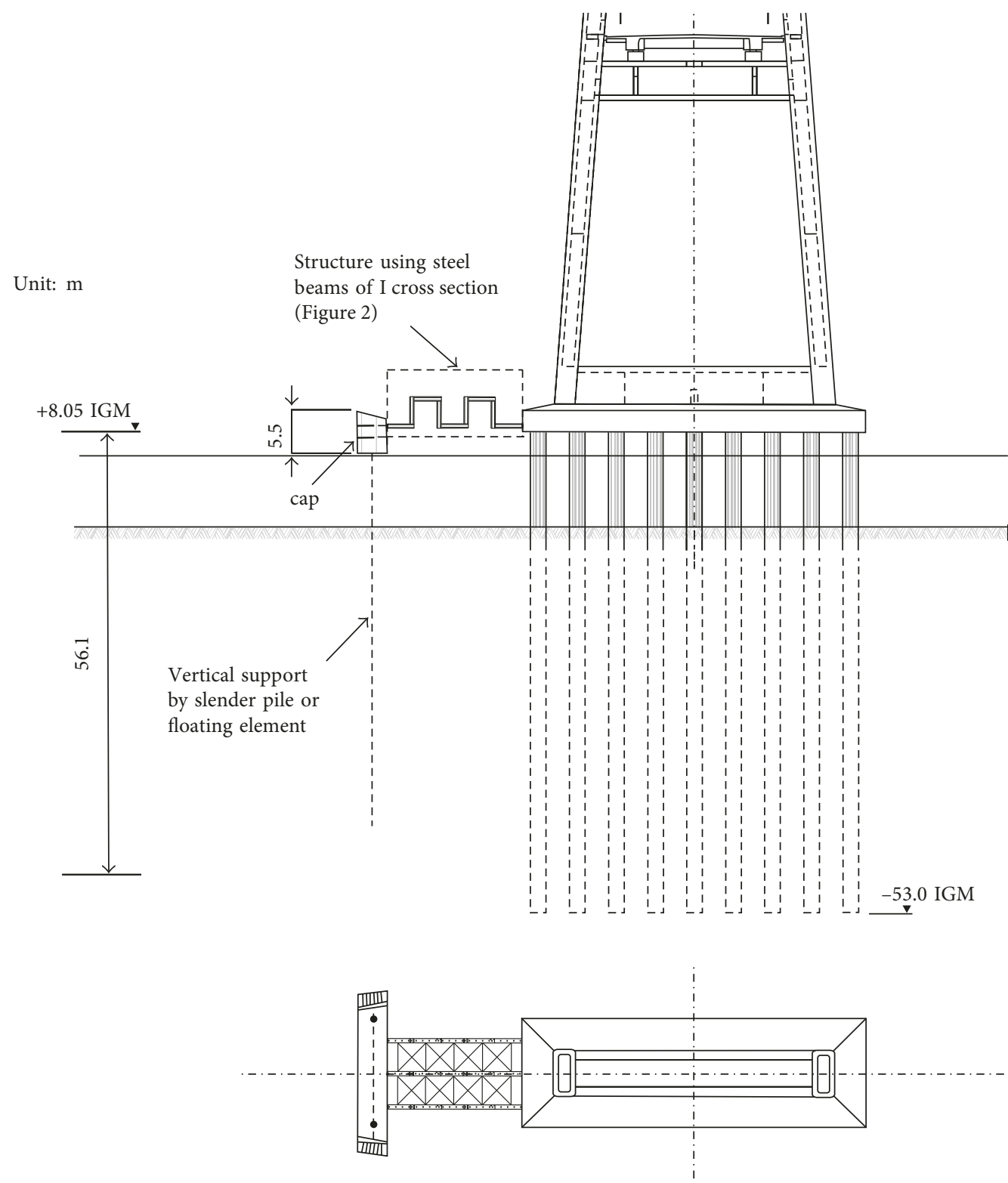

Figure 1: The structure connecting the cap and the bridge pier using steel beams of I cross section for a sample bridge pylon foundation.

the CFRP strengthening technique is very limited regarding the maximum pier displacement.

This paper aims to devise a novel crashworthy device which is comprised of a supported or floated cap connected to the pier using steel beams arranged in a frame-type manner. During a high-energy barge impact, many plastic hinges form in the proposed device, enabling it to absorb large amounts of impact energy through plastic deformations. Such crashworthy device is easy to install, maintain, and restore after an impact event. Through the choice of configuration, plastic moments, and postyield hardening, the maximum force transmitted to the main pier can be designed to not exceed an allowable force that is acceptable by the main pier.

To investigate the effectiveness of the proposed crashworthy device for barge impact, the simplified impact model previously developed by the authors is employed in this paper to conduct dynamic analysis of the device subjected to barge impact. The simplified impact model transforms the highly nonlinear full barge impact model (FBIM) into a coupled multi-degree-of-freedom model (CMM). The accuracy and efficiency of CMM were thoroughly assessed for different impact scenarios [8]. This paper employs such simplified impact model to investigate the energy dissipation capacity of the proposed device and the magnitude of impact force transmitted to the bridge pier by the steel beams during impact for different structural configurations. The parametric studies in this paper indicate that the proposed device has a large energy dissipation capacity for barge impact and can significantly reduce the maximum impact force transmitted to the bridge pier during impact. To achieve cost-optimized design of such device for a given impact scenario, a mathematical optimization model is proposed in this 


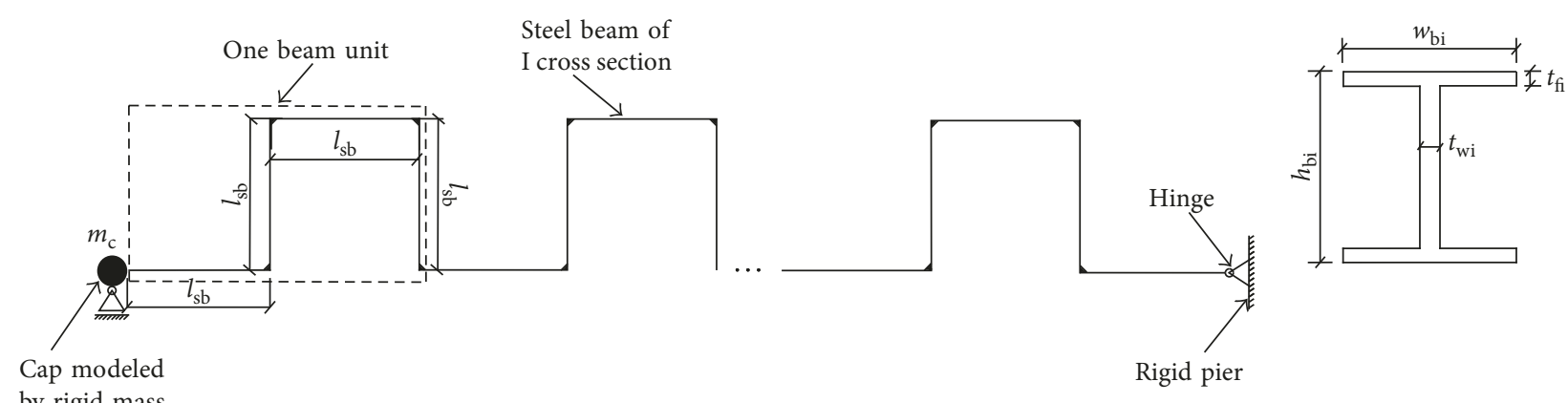

(a)

(b)

Figure 2: Configuration of (a) the cap steel beam structure and (b) I cross section of steel beams. $N_{\text {bu }}$ : number of beam units in one plane; $l_{\mathrm{sb}}$ : length of each single steel beam; $m_{\mathrm{c}}$ : cap mass.

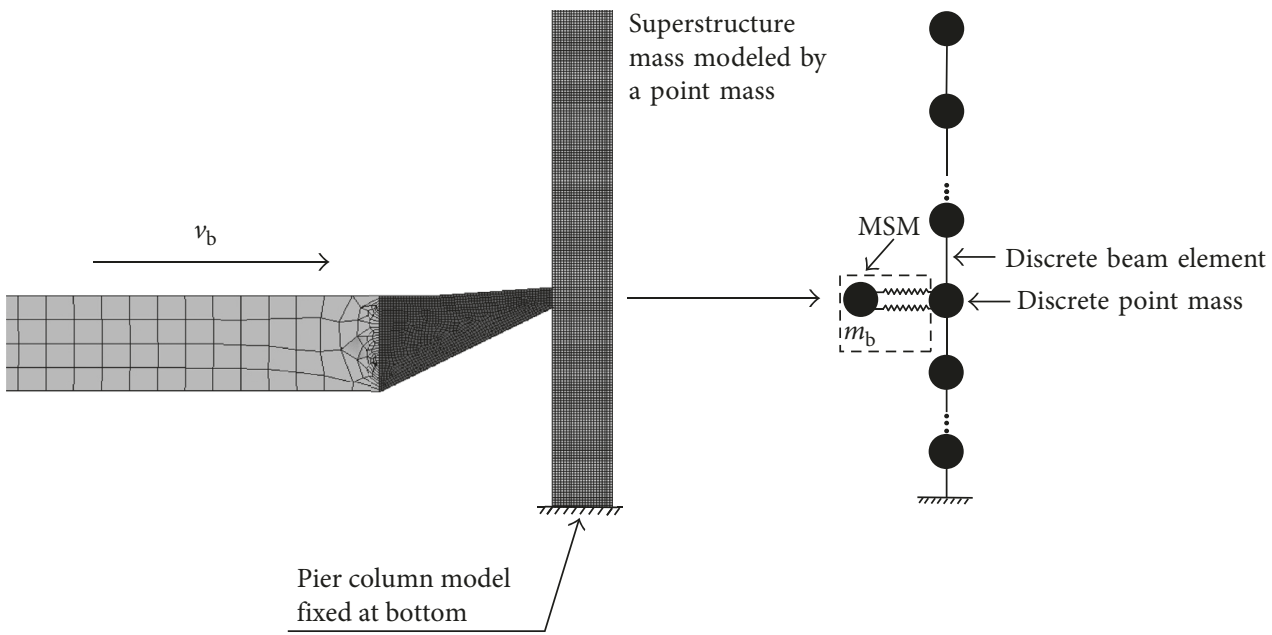

Figure 3: Transformation of FBIM (left) into CMM (right).

paper with constraints as per the prescribed design requirements. Examples presented in this paper show that the optimum configuration of the device can be obtained for different impact scenarios using the proposed optimization model.

\section{Configuration of the Device}

During a barge impact, a portion of the impact energy is transformed into the residual kinetic energy of the barge while the rest of the impact energy is dissipated through the plastic deformations of the barge and the impacted structure. In order to protect both the bridge pier and the barge, it is necessary to devise a crashworthy device which is easy to install, maintain and restore and can absorb large portions of the impact energy through plastic deformations. In this way, the energy absorbed by the barge and the pier during impact would be low, and consequently, both the barge and the pier can remain in the linear range, that is, elastic (undamaged), through the limitation of the force transmitted.

The configuration of the proposed crashworthy device is depicted in Figure 1 for a sample bridge pylon foundation to be protected. The cap structure is designed to collect the local impact forces and is vertically supported for its self-weight by a structure that does not provide a significant lateral restraint, for example, a flexible pile system or a floating structure. The cap is connected to the pylon foundation using a series of steel beams of I cross section arranged in multiple frames. The individual steel beam legs are connected bending stiff, for example, through welds, such that a force applied to the cap generates bending moments in the steel structure. Several planes of beam units can be installed to provide the energy dissipation capacity and the elastic and plastic deformation behavior desired. In Figure 1, three planes are shown, which can be braced against each other to avoid out-of-plane stability failure.

For simplification purposes, several assumptions are adopted herein: (1) the lateral resistance of the cap's supporting structure is ignored, (2) the pylon foundation is assumed to be rigid, and (3) the cap is assumed to be rigid and is modeled using a lumped mass. Based on these assumptions, the structure shown in Figure 1 can be simplified into the cap steel beam structure, as shown in Figure 2. The cap can move freely in the horizontal direction whilst its vertical movement is constrained. 


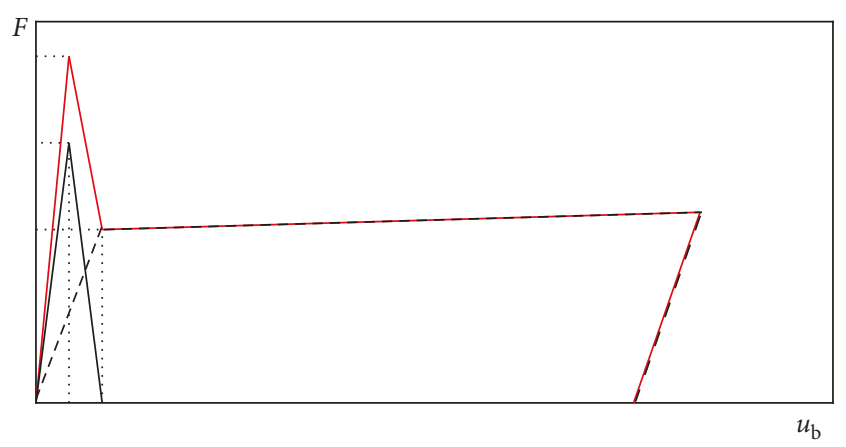

FIgURE 4: General shape of barge bow force-deformation curve. $\longrightarrow$, curve $1 ;-$, curve $2 ;--$, curve 3 .

\section{Overview of CMM}

The CMM previously developed by the authors simplifies the complex finite-element barge model into a nonlinear massspring model (MSM) and models the pier column using discrete masses and fibre beam elements [8], as shown in Figure 3, where $m_{\mathrm{b}}$ is the lumped barge mass and $v_{\mathrm{b}}$ is the impact velocity.

As per previous studies $[3,4,7]$, the force-deformation curve of the barge bow during impact (curve 1) generally includes a linear increase of impact force until the force peak is followed by an abrupt decrease when the barge bow yields, as shown in Figure 4, where $u_{\mathrm{b}}$ is the barge bow deformation and $F$ is the impact force. Then the impact force roughly reaches a plateau until the unloading stage. The shape of curve 1 can be regarded as the superposition of two curves-a triangular curve (curve 2) and a bilinear curve (curve 3), as shown in Figure 4. Two nonlinear springs which act in parallel are thus introduced to represent the barge bow resistance. The force-deformation curves of the two nonlinear springs are taken to be bilinear and triangular, respectively, as shown in Figure 5, where $u_{1}$ and $u_{2}$ are the yielding deformations of two springs, respectively; $F_{\mathrm{sy}}$ is the yielding force of the first spring; $F_{\mathrm{sp}}$ is the peak force of the second spring; and $x$ is the spring deformation. By coupling MSM with the column at the impact position, the CMM is developed to predict the dynamic barge impact process efficiently, as shown in Figure 3. The MSM parameters are determined by an optimization model which minimizes the integration error of impact force time histories determined by CMM and FBIM, respectively.

The quality of CMM regarding the prediction of impact force time history and dynamic pier responses was assessed in large detail for different impact scenarios in [8] by using FBIM as the benchmark model. The validated CMM is thus used for the studies herein.

\section{Simplified Impact Model Based on CMM}

In this section, the simplified impact model is developed based on CMM for dynamic analysis of the proposed crashworthy device subjected to barge impact. As shown in Figure 6, the steel beams are modeled using discrete masses and fibre beam elements. The MSM is coupled with the cap which is expected to contact with the barge when impact occurs. It is assumed in

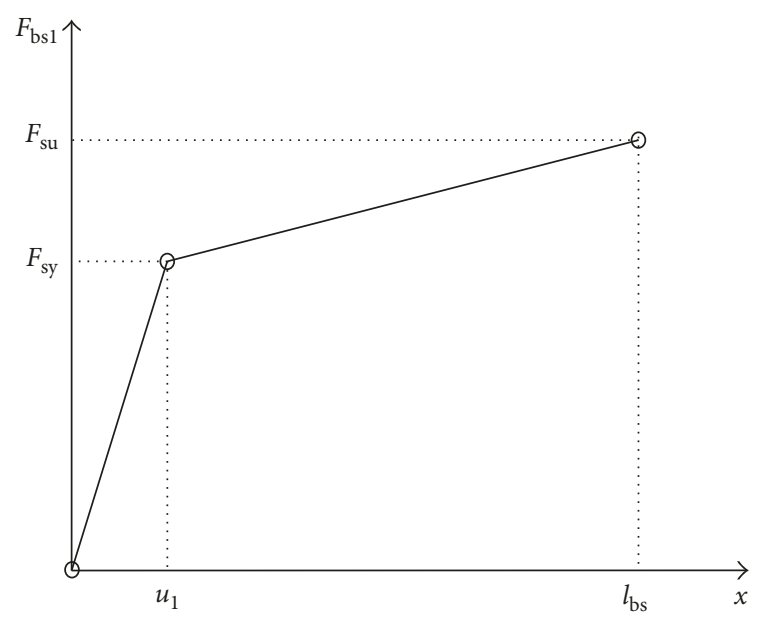

(a)

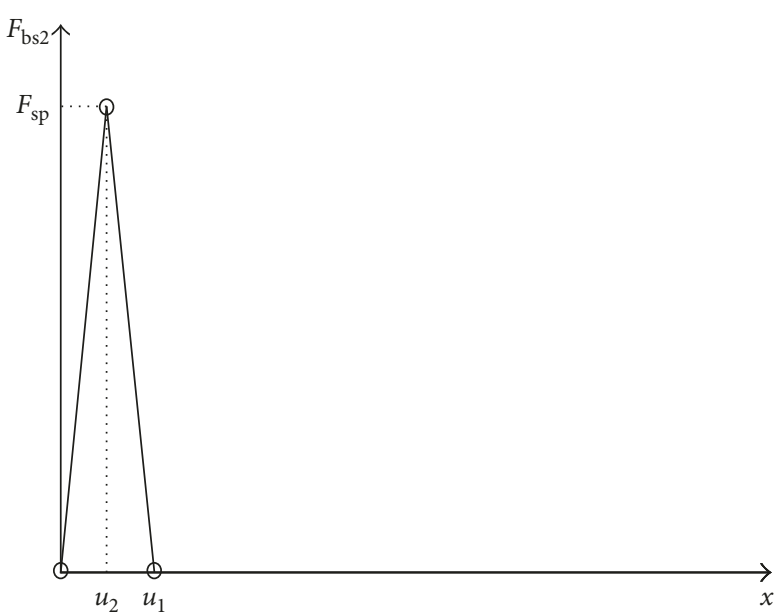

(b)

FIGURE 5: Bilinear spring model (a) and triangular spring model (b) used in MSM [8].

this study that the beam elements undergo no shear deformations or torsional deformations. The stress-strain curve of the beam steel is bilinear in this study.

The MATLAB code was written with the fibre method for solving the numerical model illustrated in Figure 6. The code was previously verified by detailed finite-element simulation results from LS-DYNA [8]. Geometric nonlinearity of beam elements is analyzed using the corotational approach for problems of large displacements and small strains. The basic idea is to decompose the motion of the element into rigid body part and pure deformational part. A local coordinate system, which moves and rotates with the element's overall rigid body motion, is defined, and the deformational part is measured under this local coordinate system [15].

\section{Parametric Studies}

The effectiveness of the proposed device is investigated in this section by parametric studies using the simplified impact model. The cap surface which contacts with the barge is flat and is $3.0 \mathrm{~m}$ in width. The bridge pier is flat and $6.0 \mathrm{~m}$ in 


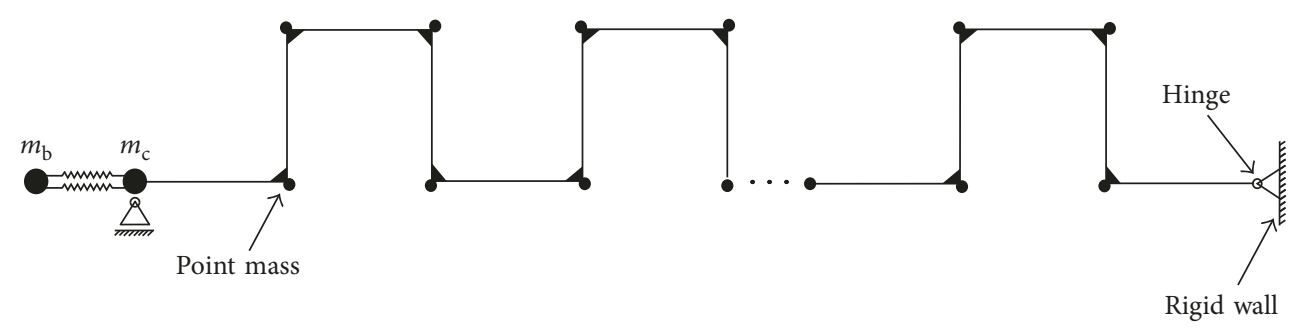

FIgURE 6: Simplified impact model based on CMM for dynamic analysis of the proposed device subjected to barge impact.

TABle 1: Prespecified parameters for parametric studies of the device.

\begin{tabular}{lcc}
\hline Member & Parameter & Value \\
\hline Barge & $m_{\mathrm{b}}$ = barge mass & 1723.7 ton \\
& $v_{\mathrm{b}}=$ impact velocity & $2.0 \mathrm{~m} / \mathrm{s}$ \\
$3.0 \mathrm{~m}$ & $100.0 \mathrm{ton}$ \\
Cap & $w_{\mathrm{c}}=$ cap width & 1 \\
& $m_{\mathrm{c}}=$ cap mass & $15.0 \mathrm{~m}$ \\
& $N_{\mathrm{pl}}=$ number of planes of beam units & $8020.0 \mathrm{~kg} / \mathrm{m}^{3}$ \\
Steel beams & $l_{\mathrm{csb}}=$ total length of beam units in one plane & $200.0 \mathrm{GPa}$ \\
& $\rho_{\mathrm{bs}}=$ mass density of beam steel & $1.5 \mathrm{GPa}$ \\
& $E_{\mathrm{bs}}=$ elastic modulus of beam steel & 0.25 \\
Pier & $E_{\mathrm{t}}^{\mathrm{bs}}=$ tangent modulus of beam steel & $6.0 \mathrm{~m}$ \\
\hline
\end{tabular}

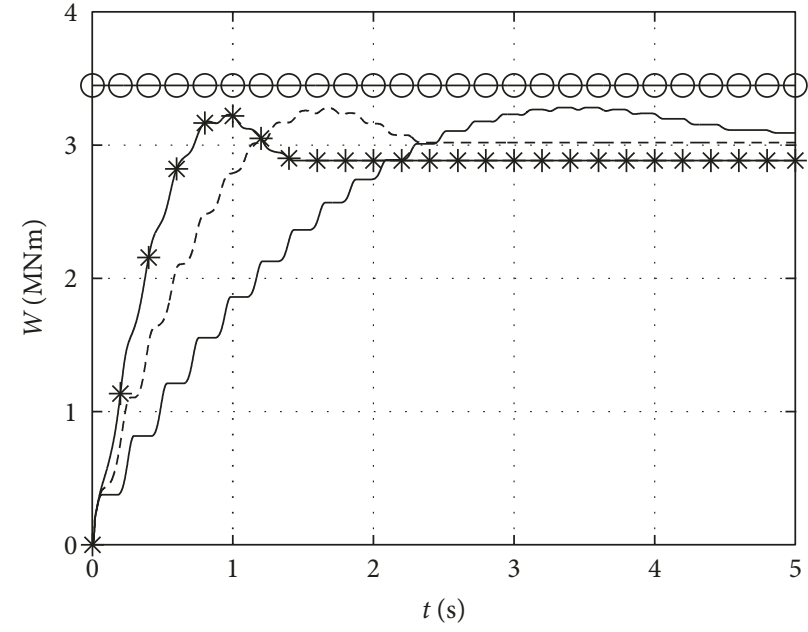

(a)

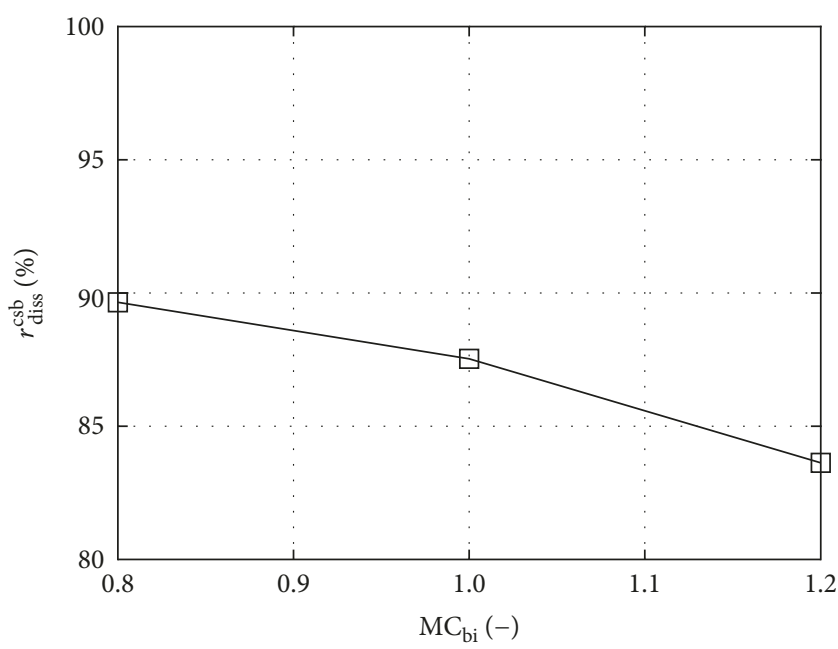

(b)

Figure 7: Time histories of energy absorbed by the device (a) corresponding to different beam cross-section dimensions and the ratio of energy absorbed by the device after impact to the total impact energy, respectively, versus $\mathrm{MC}_{\mathrm{bi}}(\mathrm{b}) .-, W_{\mathrm{diss}}^{\mathrm{csb}}\left(\mathrm{MC}_{\mathrm{bi}}=0.8\right) ;----, W_{\text {diss }}^{\text {csb }}$ $\left(\mathrm{MC}_{\mathrm{bi}}=1.0\right) ;-*-, W_{\mathrm{diss}}^{\mathrm{csb}}\left(\mathrm{MC}_{\mathrm{bi}}=1.2\right) ;-\mathrm{O}-, W_{\text {total }} ; \square$, the ratio of energy absorbed by the device after impact to the total impact energy.

width. The cap mass $\left(m_{\mathrm{c}}\right)$ is taken to be 100.0 ton. The total length of the beam units in one plane $\left(l_{\mathrm{csb}}\right)$ is taken to be $15.0 \mathrm{~m}$. The number of planes of beam units $\left(N_{\mathrm{pl}}\right)$ is taken to be one in this study. The information of the prespecified parameters regarding the device is tabulated in Table 1.

Three parameters, that is, beam cross-section dimension, yielding strength of beam steel $\left(f_{\mathrm{y}}^{\mathrm{bs}}\right)$, and number of beam units in one plane $\left(N_{\mathrm{bu}}\right)$, are considered for the parametric studies herein. For comparison purposes, the following baseline simulation is conducted: beam cross-section dimension as follows: $h_{\mathrm{bi}}=0.75 \mathrm{~m}, w_{\mathrm{bi}}=0.50 \mathrm{~m}, t_{\mathrm{fi}}=0.05 \mathrm{~m}$, and $t_{\mathrm{wi}}=0.03 \mathrm{~m}$; beam steel yielding strength of $350.0 \mathrm{MPa}$; and beam unit number of two in one plane. The parameter $\mathrm{MC}_{\mathrm{bi}}$, which means the ratio of the studied beam cross-section dimensional parameters, that is, $h_{\mathrm{bi}}, w_{\mathrm{bi}}, t_{\mathrm{fi}}$, and $t_{\mathrm{wi}}$, to the respective beam cross-section dimensional parameters used for the baseline simulation, is denoted herein.

5.1. Beam Cross-Section Dimension. Three beam crosssection dimensions corresponding to $\mathrm{MC}_{\mathrm{bi}}$ of $0.8,1.0$, and 1.2 , respectively, are considered herein. The energy absorbed by the device $\left(W_{\text {diss }}^{\text {csb }}\right)$ during impact corresponding to each beam cross-section dimension is shown in Figure 7, where the total impact energy $\left(W_{\text {total }}\right)$ and the ratio $\left(r_{\text {diss }}^{\text {csb }}\right)$ of energy 


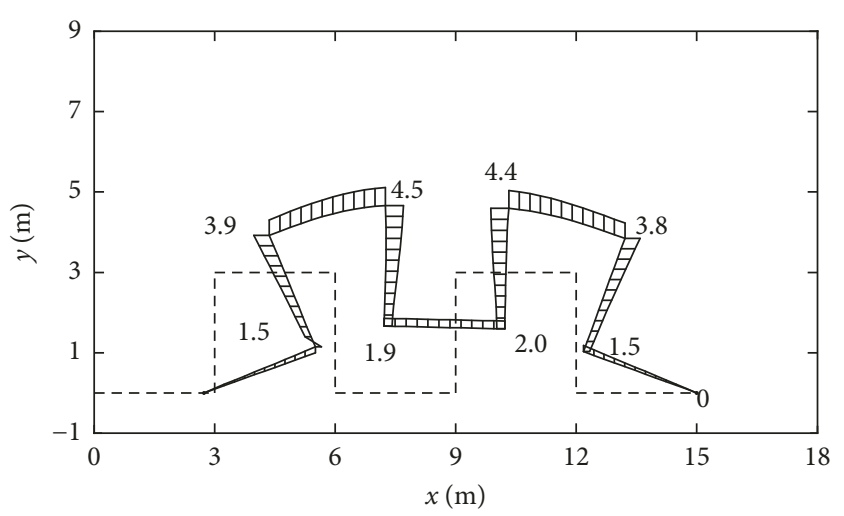

(a)

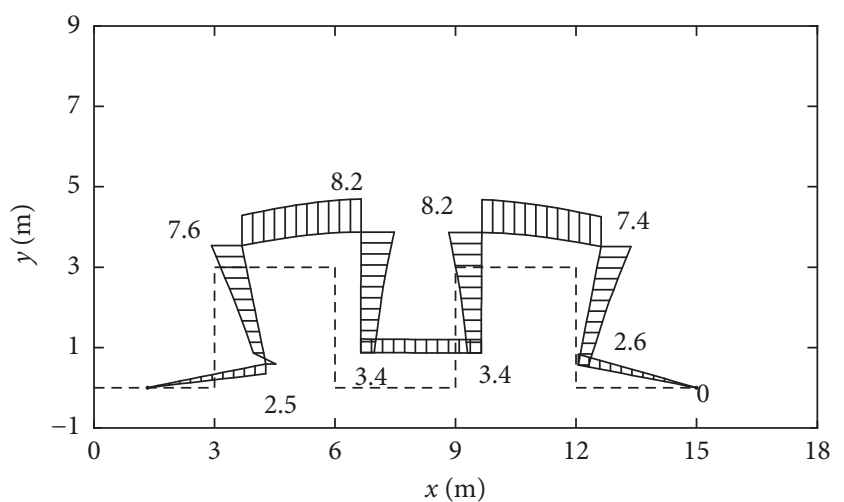

(b)

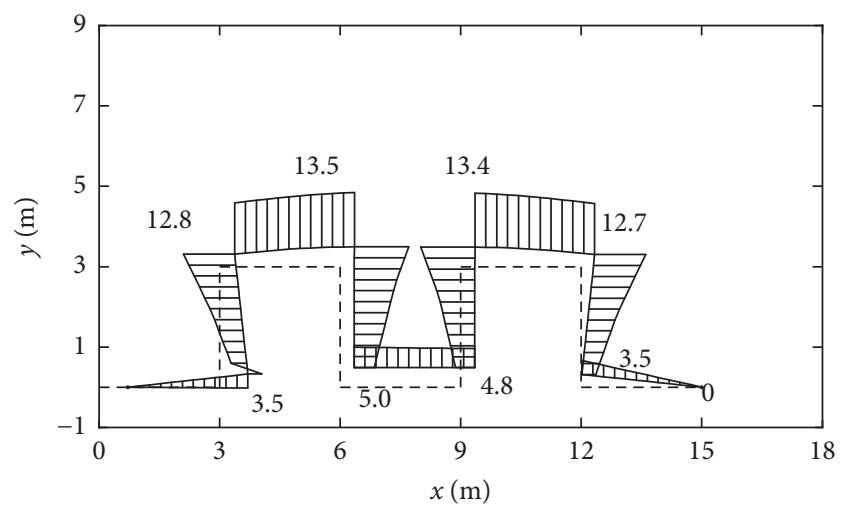

(c)

FIgURE 8: Maximum bending moment diagrams of the structures during impact and deflections of the structures after impact corresponding to different beam cross-section dimensions (unit: $\mathrm{MNm}$ ). - - , original shape of the device; —_ deformed shape of the device. (a) $\mathrm{MC}_{\mathrm{bi}}=0.8$; (b) $\mathrm{MC}_{\mathrm{bi}}=1.0$; (c) $\mathrm{MC}_{\mathrm{bi}}=1.2$.

absorbed by the device after impact to the total impact energy are also presented. Figure 7 shows that a large portion of the impact energy is absorbed by the device and that the increase of beam cross-section dimension reduces the energy absorbed by the device due to the decrease of structure deformation caused by the increase of structure stiffness, as shown in Figure 8, where the maximum bending moment diagram of the structure during impact and the structure deflection after impact corresponding to each beam crosssection dimension are presented.

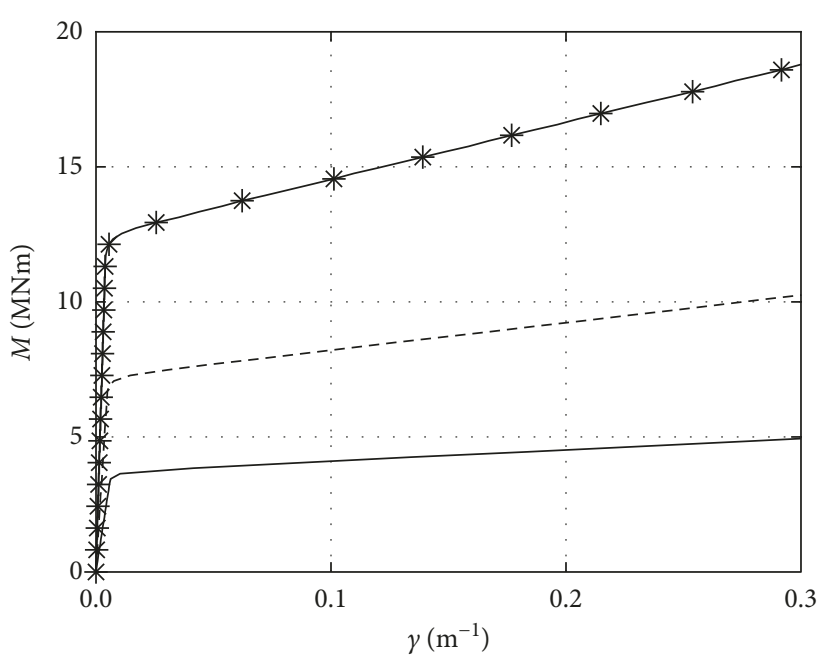

(a)

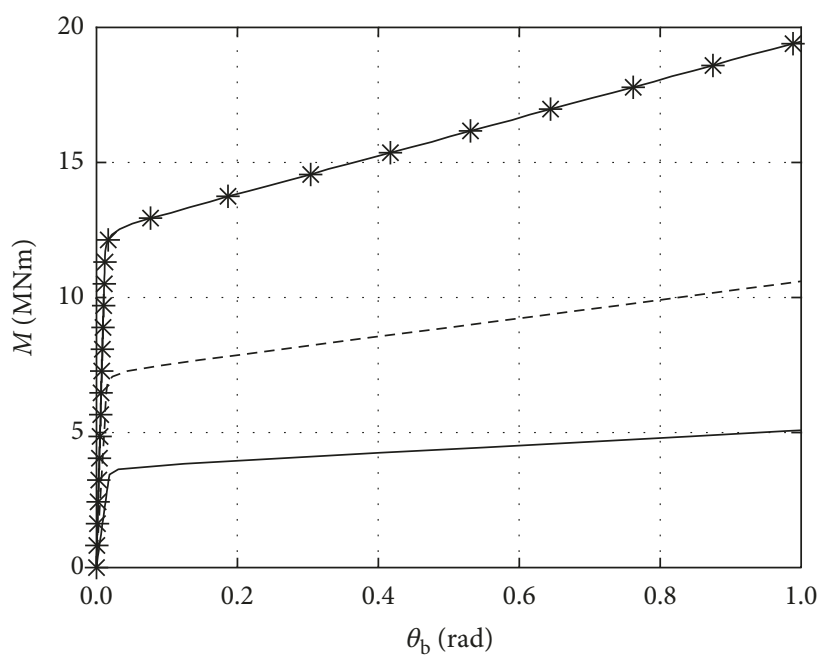

(b)

FIGURE 9: Moment-curvature relationships of the I cross sections (a) and moment-rotation relationships of single steel beams (b) corresponding to different beam cross-section dimensions. $\longrightarrow, \mathrm{MC}_{\mathrm{bi}}=0.8 ;---, \mathrm{MC}_{\mathrm{bi}}=1.0 ;-*-, \mathrm{MC}_{\mathrm{bi}}=1.2$.

The moment-curvature relationship of each beam cross section and the moment-rotation relationship of a single steel beam corresponding to each beam cross-section dimension are shown in Figure 9, where $\gamma$ is the curvature of beam cross section and $\theta_{\mathrm{b}}$ is the relative rotation angle of two boundary sections of a single steel beam. Figures 8 and 9 show that the plastic hinges which form during impact are located at the upper part of the structure, that is, the horizontal beams at the top and the upper part of the vertical beams, where the maximum bending moment exceeds the corresponding yielding moment of beam cross section. The formation of plastic hinges enables the device to absorb a large portion of energy during impact, as shown in Figure 7. The lower part of the structure, that is, the horizontal beams at the bottom and the lower part of the vertical beams, undergoes only elastic deformations, as Figure 8 shows. 
The time histories of impact force on the pier with the device corresponding to each beam cross-section dimension and without the device, respectively, together with the reduction ratio $\left(r_{\mathrm{f}}\right)$ of maximum impact force when the device is used, are shown in Figure 10, which shows that the maximum impact force can be significantly reduced when the device is used. The increase of beam cross section would increase the magnitude of impact force due to the increase of cross-section fibres.

5.2. Yielding Strength of Beam Steel. Three steel yielding strengths of $250.0 \mathrm{MPa}, 350.0 \mathrm{MPa}$, and $450.0 \mathrm{MPa}$, respectively, are considered herein. The energy absorbed by the device ( $\left.W_{\text {diss }}^{\text {csb }}\right)$ during impact corresponding to each steel yielding strength is shown in Figure 11, where the total impact energy $\left(W_{\text {total }}\right)$ and the ratio $\left(r_{\text {diss }}^{\text {csb }}\right)$ of energy absorbed by the device after impact to the total impact energy are also presented. Figure 11 shows that the increase of steel yielding strength reduces the energy absorbed by the device during impact. This is because the structure resistance increases with the increase of steel yielding strength and consequently the structure undergoes smaller deformations, as shown in Figure 12.

The time histories of impact force on the bridge pier with the device corresponding to each steel yielding strength and without the device, respectively, together with the reduction ratio of maximum impact force when the device is used, are shown in Figure 13, which shows that the increase of steel yielding strength would increase the magnitude of impact force on the pier due to the increase of structure resistance.

5.3. Number of Beam Units. The devices of one beam unit, two beam units, and three beam units, respectively, are considered herein. The energy absorbed by the device $\left(W_{\text {diss }}^{\text {csb }}\right)$ during impact corresponding to each beam unit number is shown in Figure 14, where the total impact energy $\left(W_{\text {total }}\right)$ and the ratio $\left(r_{\text {diss }}^{\text {csb }}\right)$ of energy absorbed by the device after impact to the total impact energy are also presented. Figure 14 shows that the increase of beam unit number slightly reduces the energy absorbed by the device. This is because the structure becomes stiffer when more beam units are used, as indicated in Figures 15 and 16 which show that the structure undergoes smaller deflections and smaller deformations during impact when more beam unit number is used.

The time histories of impact force on the pier with the device corresponding to each beam unit number and without the device, respectively, together with the reduction ratio $\left(r_{\mathrm{f}}\right)$ of maximum impact force when the device is used, are shown in Figure 17, which shows that the magnitude of impact force on the pier increases when beam unit number increases due to the increase of structure stiffness.

\section{Cost-Optimized Design of the Device}

The studies in the previous section have shown the great potentiality of the proposed crashworthy device for pier protection from barge impact due to its large energy dissipation capacity during impact. In order to achieve cost-optimized

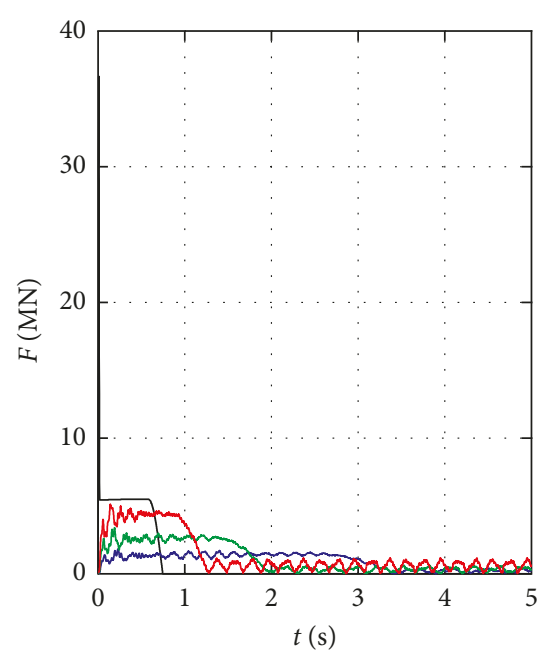

(a)

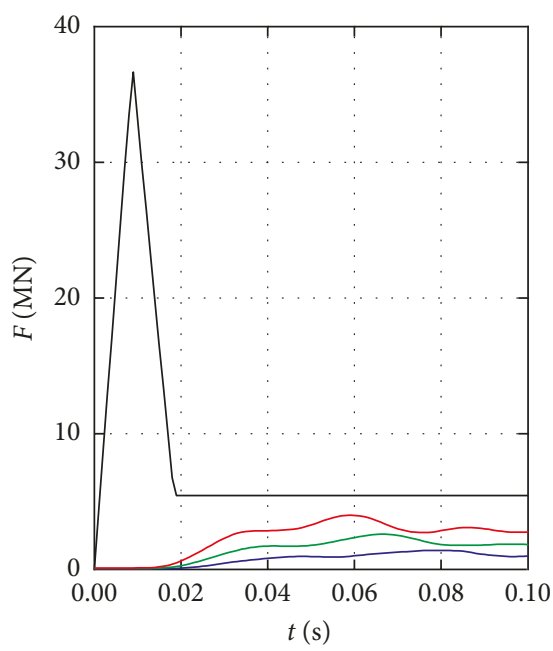

(b)

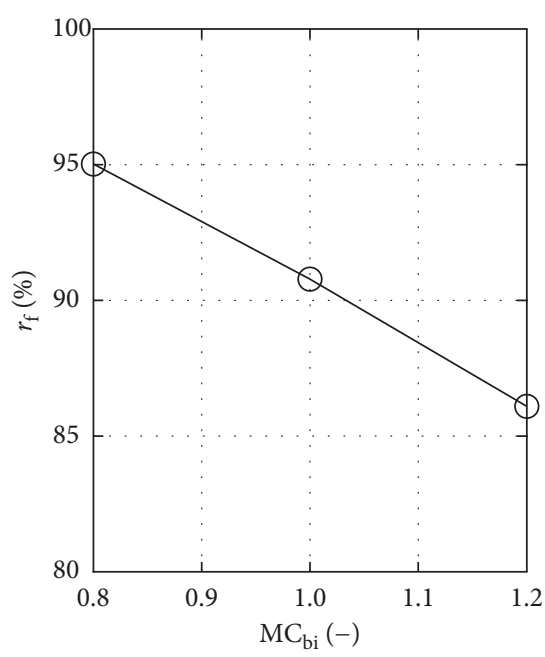

(c)

FIGURE 10: Impact force time histories on the bridge pier for the whole impact process (a), for the first $0.10 \mathrm{~s}$ of impact process (b) corresponding to different beam cross-section dimensions, and the reduction ratio of maximum impact force versus $\mathrm{MC}_{\mathrm{bi}}$ (c). - , without the device; $\longrightarrow, \mathrm{MC}_{\mathrm{bi}}=0.8 ;-, \mathrm{MC}_{\mathrm{bi}}=1.0 ; \longrightarrow, \mathrm{MC}_{\mathrm{bi}}=1.2$. 


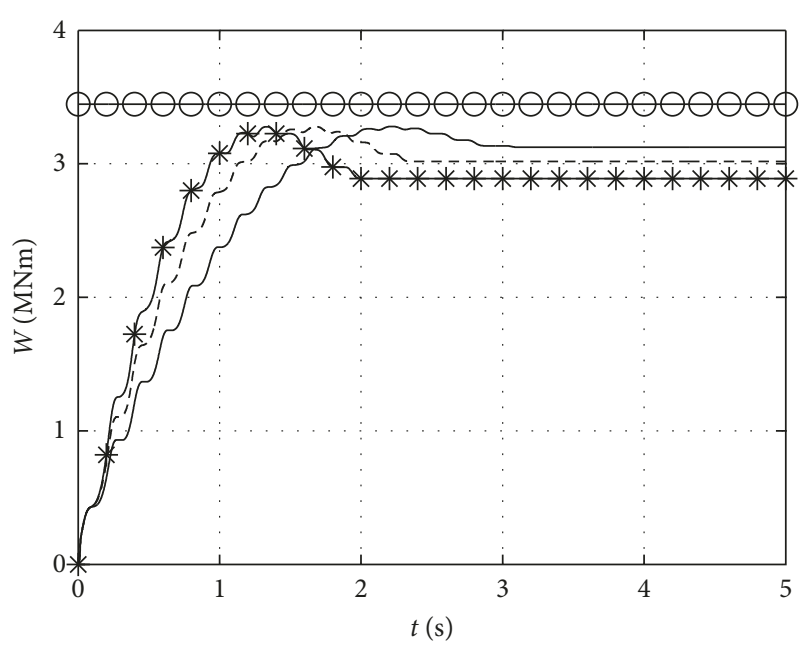

(a)

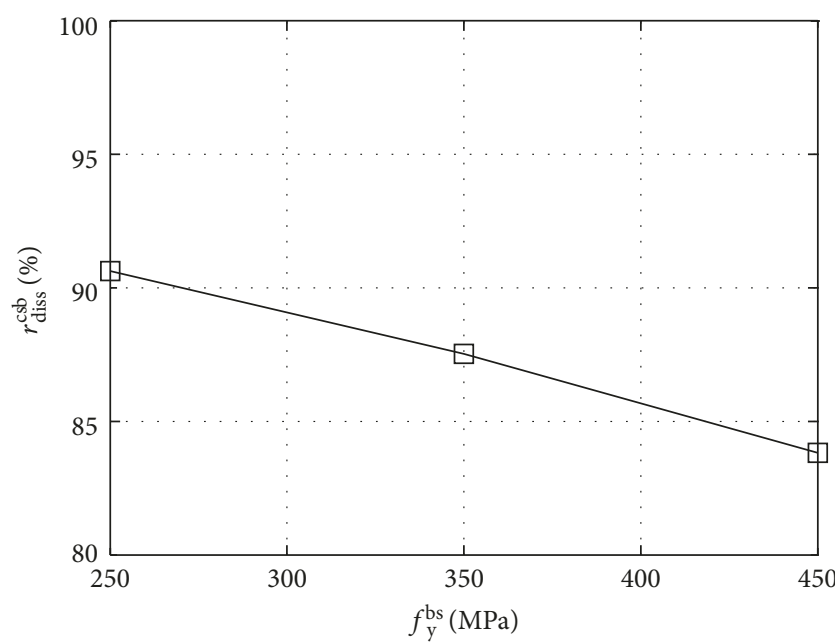

(b)

FIgURE 11: Time histories of energy absorbed by the device (a) corresponding to different yielding strengths of beam steel and the ratio of energy absorbed by the device after impact to the total impact energy, respectively, versus yielding strength of beam steel $f_{\mathrm{y}}^{\mathrm{bs}}(\mathrm{b}) .-\longrightarrow, W_{\text {diss }}^{\text {csb }}\left(f_{\mathrm{y}}^{\mathrm{bs}}=250.0 \mathrm{MPa}\right) ;-\cdots, W_{\text {diss }}^{\mathrm{csb}}$ $\left(f_{\mathrm{y}}^{\mathrm{bs}}=350.0 \mathrm{MPa}\right) ;-*-, W_{\text {diss }}^{\text {csb }}\left(f_{\mathrm{y}}^{\mathrm{bs}}=450.0 \mathrm{MPa}\right) ;-0-, W_{\text {total }} ; \square$, the ratio of energy absorbed by the device after impact to the total impact energy.

design of such device for a given impact scenario, a mathematical optimization model is proposed in this section with constraints as per the prescribed design requirements.

6.1. Mathematical Optimization Model. For a given barge mass $\left(m_{\mathrm{b}}\right)$ and impact velocity $\left(v_{\mathrm{b}}\right)$, when the number of planes of beam units $\left(N_{\mathrm{pl}}\right)$, the yielding strength of beam steel $\left(f_{\mathrm{y}}^{\mathrm{bs}}\right)$, and the maximum allowable impact force $F_{\max }^{\text {allow }}$ on the bridge pier are specified, the device can be designed in such a way that the design requirements are satisfied and the required cost is minimized by using minimum amount of steel. The design of the device can thus be transformed into an optimization problem where the number of beam units in one plane $\left(N_{\mathrm{bu}}\right)$, the four dimensional parameters of the I cross section, that is, $h_{\mathrm{bi}}, w_{\mathrm{bi}}, t_{\mathrm{fi}}$, and $t_{\mathrm{wi}}$, and the length of each

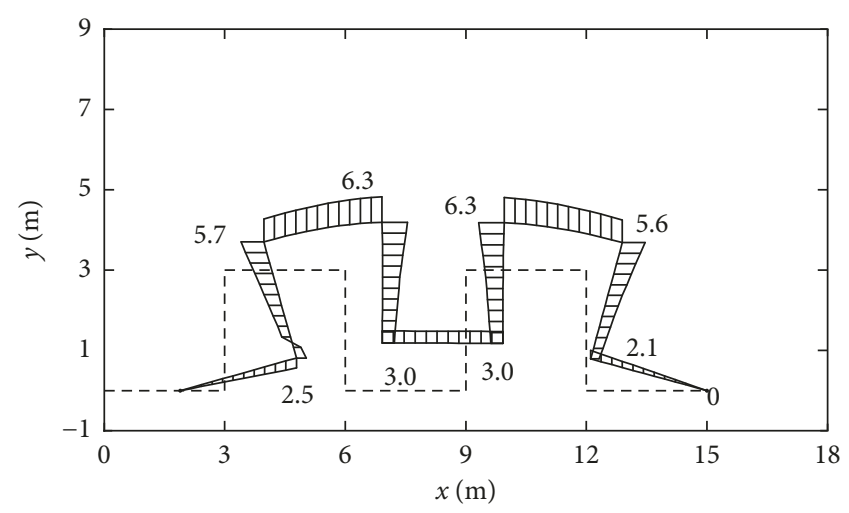

(a)

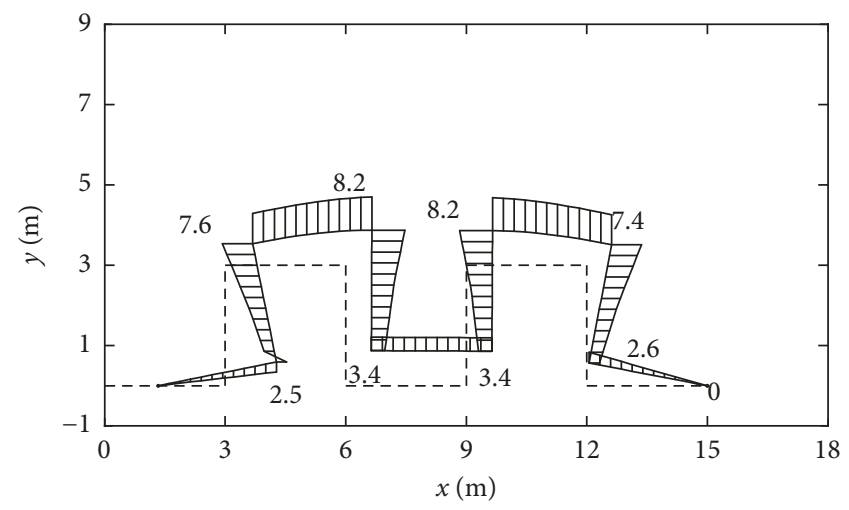

(b)

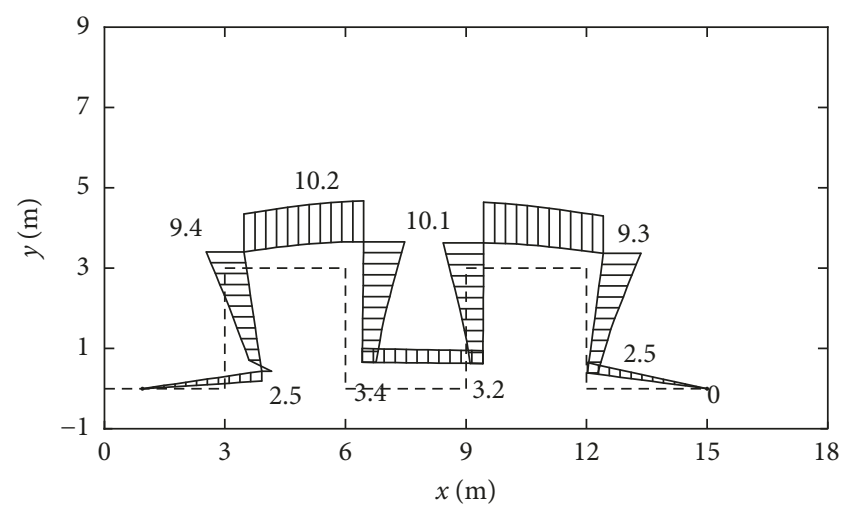

(c)

FIGURE 12: Maximum bending moment diagrams of the structures during impact and deflections of the structures after impact corresponding to different yielding strengths of beam steel (unit: $\mathrm{MNm}$ ). _ - , original shape of the device; —_, deformed shape of the device. (a) $f_{\mathrm{y}}^{\mathrm{bs}}=250.0 \mathrm{MPa}$; (b) $f_{\mathrm{y}}^{\mathrm{bs}}=350.0 \mathrm{MPa}$; (c) $f_{\mathrm{y}}^{\mathrm{bs}}=450.0 \mathrm{MPa}$.

single steel beam $l_{\mathrm{sb}}$ are optimized. For simplification purposes, the four dimensional parameters of the I cross section are assumed to satisfy the relationships as tabulated in Table 2.

The optimization model and the corresponding constraints are described as follows:

minimize:

$$
m_{\mathrm{sb}}=\left(4 N_{\mathrm{bu}}+1\right) l_{\mathrm{sb}} A_{\mathrm{I}} N_{\mathrm{pl}} \rho_{\mathrm{bs}},
$$




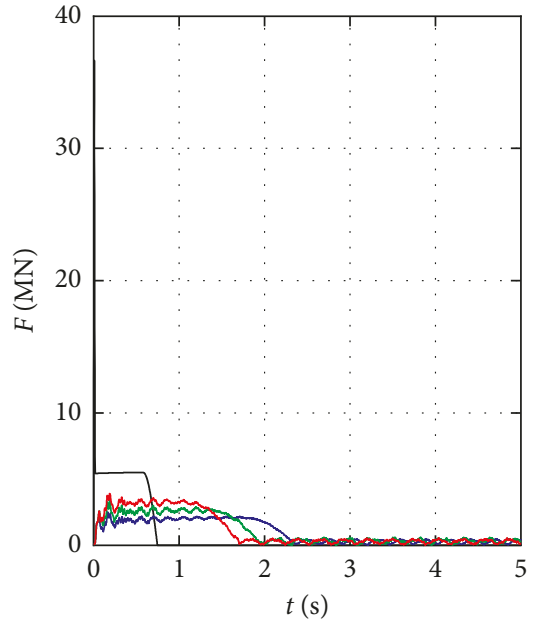

(a)

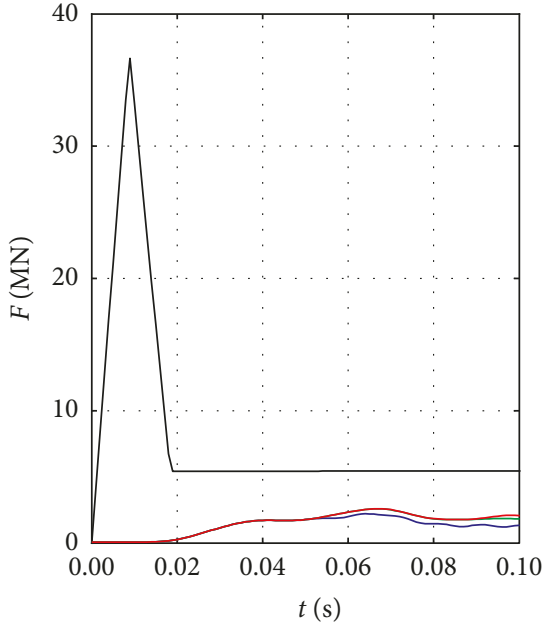

(b)

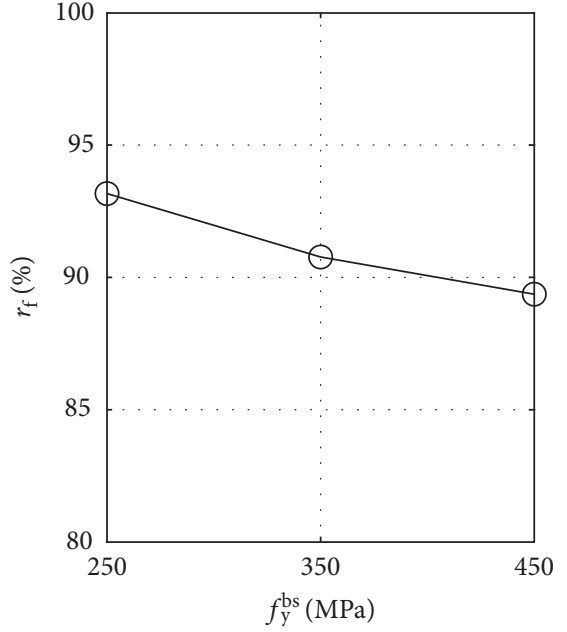

(c)

FIGURE 13: Impact force time histories on the bridge pier for the whole impact process (a), for the first $0.10 \mathrm{~s}$ of impact process (b) corresponding to different yielding strengths of beam steel and the reduction ratio of maximum impact force versus yielding strength of beam steel $f_{\mathrm{y}}^{\mathrm{bs}}(\mathrm{c})$. - , without the device; $\longrightarrow, f_{\mathrm{y}}^{\mathrm{bs}}=250.0 \mathrm{MPa} ;-, f_{\mathrm{y}}^{\mathrm{bs}}=350.0 \mathrm{MPa} ;-, f_{\mathrm{y}}^{\mathrm{bs}}=450.0 \mathrm{MPa}$.

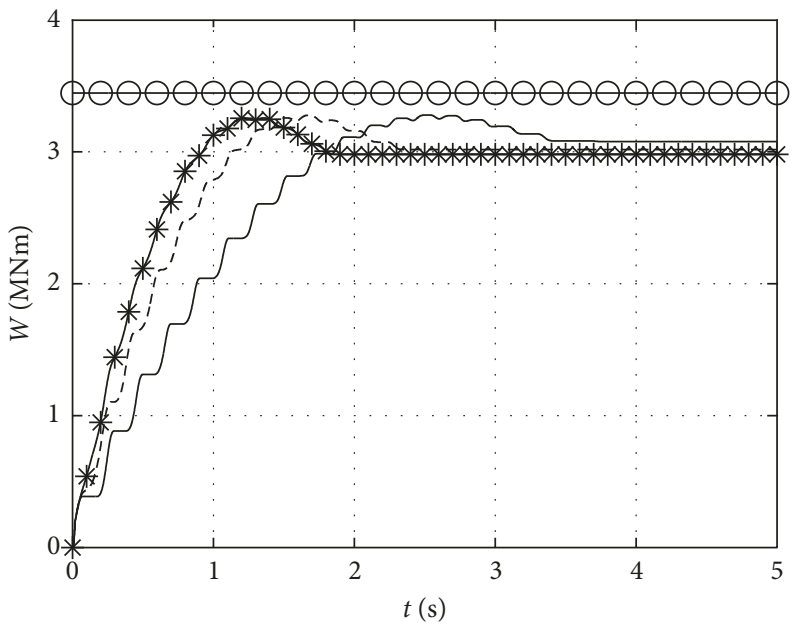

(a)

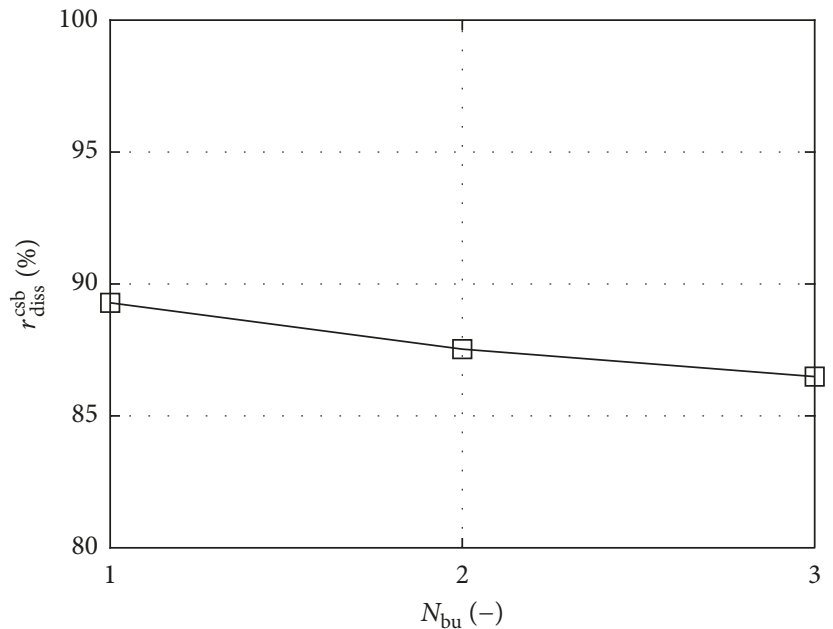

(b)

FIgURE 14: Time histories of energy absorbed by the device (a) corresponding to different beam unit numbers and the ratio of energy absorbed by the device after impact to the total impact energy, respectively, versus beam unit number in one plane $N_{\text {bu }}$ (b). $W_{\text {diss }}^{\text {csb }}\left(N_{\text {bu }}=1\right) ;---, W_{\text {diss }}^{\text {csb }}\left(N_{\text {bu }}=2\right) ;-*-, W_{\text {diss }}^{\text {csb }}\left(N_{\text {bu }}=3\right) ;-0-, W_{\text {total }} ; \square$, the ratio of energy absorbed by the device after impact to the total impact energy.

subject to:

$$
\begin{gathered}
5 h_{\mathrm{bi}} \leq l_{\mathrm{sb}}, \\
N_{\mathrm{bu}}^{\mathrm{l}} \leq N_{\mathrm{bu}} \leq N_{\mathrm{bu}}^{\mathrm{u}}, \\
h_{\mathrm{bi}}^{\mathrm{l}} \leq h_{\mathrm{bi}} \leq h_{\mathrm{bi}}^{\mathrm{u}}, \\
l_{\mathrm{sb}}^{\mathrm{l}} \leq l_{\mathrm{sb}} \leq l_{\mathrm{sb}}^{\mathrm{u}}, \\
F_{\max } \leq F_{\max }^{\mathrm{allow}}, \\
D_{\mathrm{cap}}^{\max } \leq D_{\max }^{\mathrm{allow}}=N_{\mathrm{bu}} l_{\mathrm{sb}},
\end{gathered}
$$

where $m_{\mathrm{sb}}$ is the total mass of steel beams (ton), $A_{\mathrm{I}}$ is the area of the I cross section $\left(\mathrm{m}^{2}\right), \rho_{\mathrm{bs}}$ is the mass density of beam steel (ton $/ \mathrm{m}^{3}$ ), $N_{\mathrm{bu}}^{\mathrm{l}}$ and $N_{\mathrm{bu}}^{\mathrm{u}}$ are the lower bound and upper bound of the number of beam units in one plane (-), respectively, $h_{\mathrm{bi}}^{\mathrm{l}}$ and $h_{\mathrm{bi}}^{\mathrm{u}}$ are the lower bound and upper bound of the depth of the I cross section $(\mathrm{m})$, respectively, $l_{\mathrm{sb}}^{\mathrm{l}}$ and $l_{\mathrm{sb}}^{\mathrm{u}}$ are the lower bound and upper bound of beam length $(\mathrm{m})$, respectively, $F_{\max }$ is the maximum impact force on the bridge pier during impact $(\mathrm{MN}), D_{\text {cap }}^{\max }$ is the maximum cap displacement during impact $(\mathrm{m})$, and $D_{\max }^{\text {allow }}$ is the maximum allowable cap displacement $(\mathrm{m})$. The value of $D_{\max }^{\text {allow }}$ is taken to be $N_{\mathrm{bu}} l_{\mathrm{sb}}$ to avoid the contact of adjacent vertical beams during impact. 


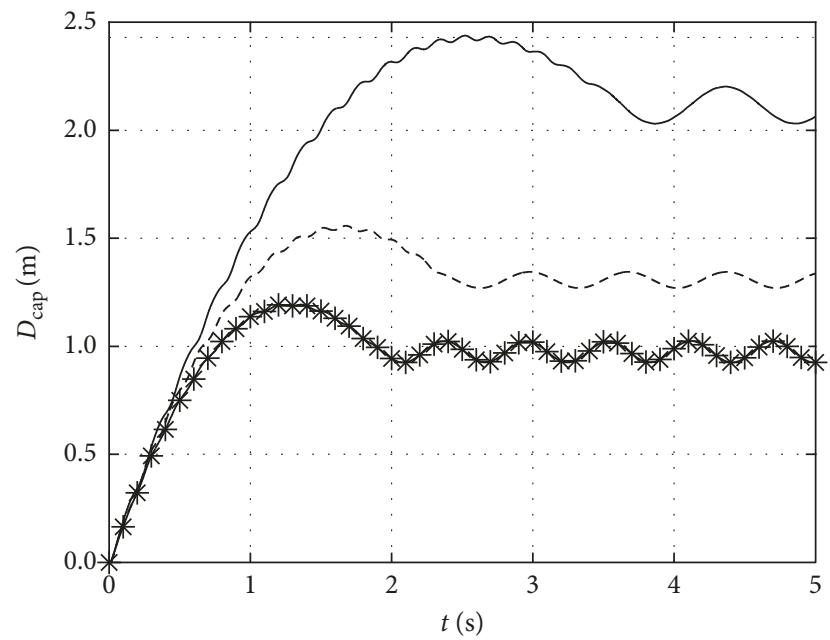

(a)

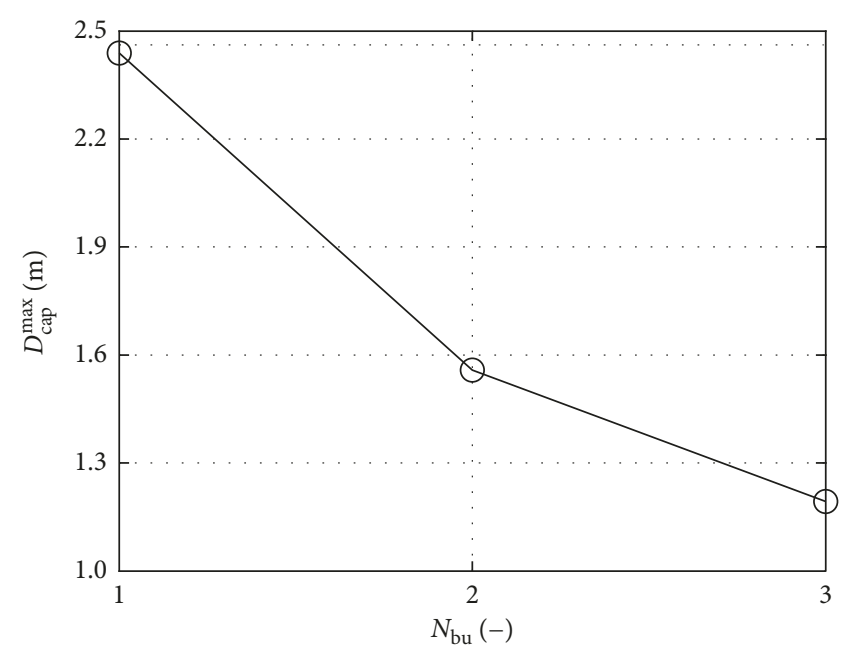

(b)

Figure 15: Time histories of cap displacement corresponding to different beam unit numbers (a) and maximum cap displacement $D_{\text {cap }}^{\max }$ versus beam unit number in one plane $N_{\mathrm{bu}}(\mathrm{b}) .-, N_{\mathrm{bu}}=1 ;----, N_{\mathrm{bu}}=2 ;-*-, N_{\mathrm{bu}}=3$.

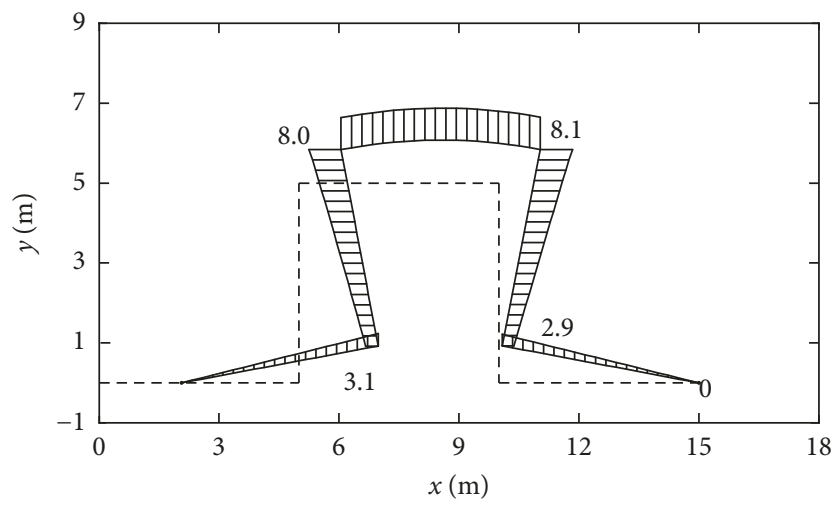

(a)

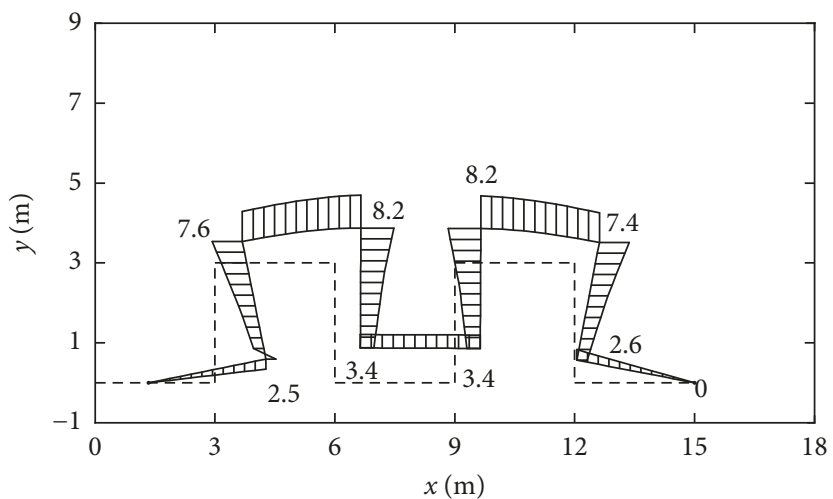

(b)

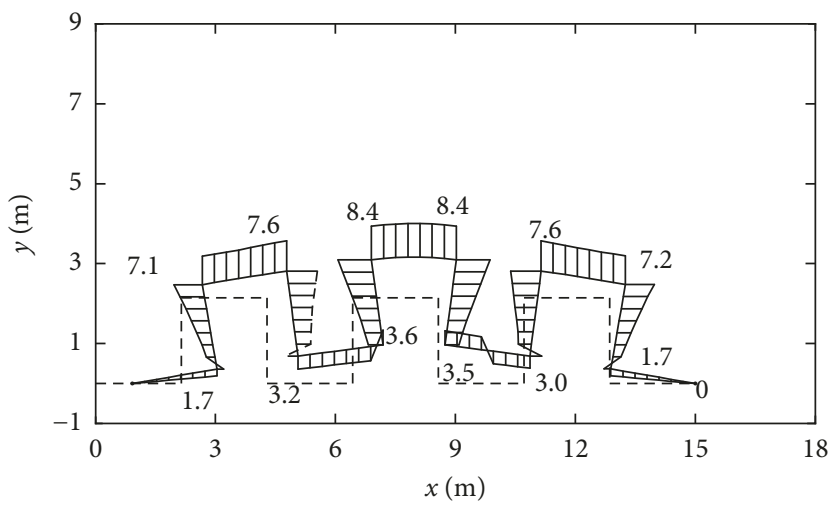

(c)

FIGURE 16: Maximum bending moment diagrams of the structures during impact and deflections of the structures after impact corresponding to different beam unit numbers (unit: MNm). - , original shape of the device; _ _ deformed shape of the device. (a) $N_{\mathrm{bu}}=1$; (b) $N_{\text {bu }}=2 ;$ (c) $N_{\text {bu }}=3$.

Three variables, that is, $N_{\mathrm{bu}}, h_{\mathrm{bi}}$, and $l_{\mathrm{sb}}$, are included in the optimization process. The sequential quadratic programming (SQP) [16] is used for solving the proposed constrained optimization problem.
6.2. Application Example. In this section, the optimum configurations of the devices corresponding to several different impact scenarios are obtained using the proposed optimization model. The combinations of three barge 


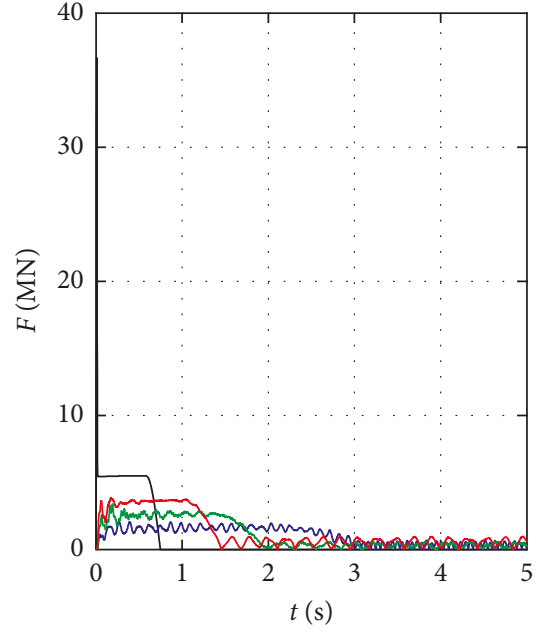

(a)

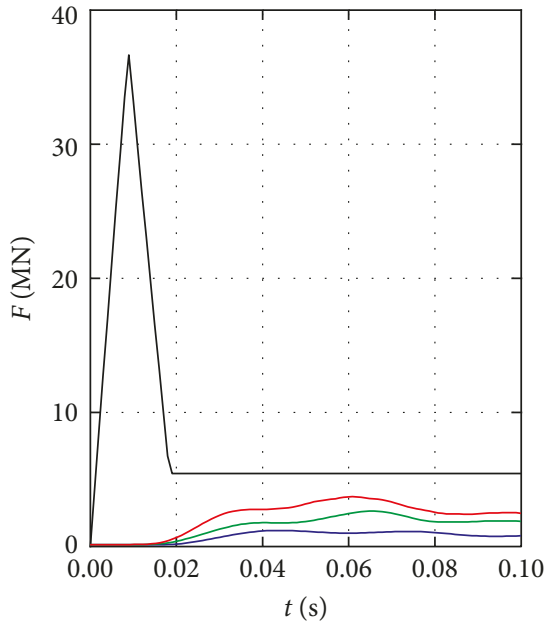

(b)

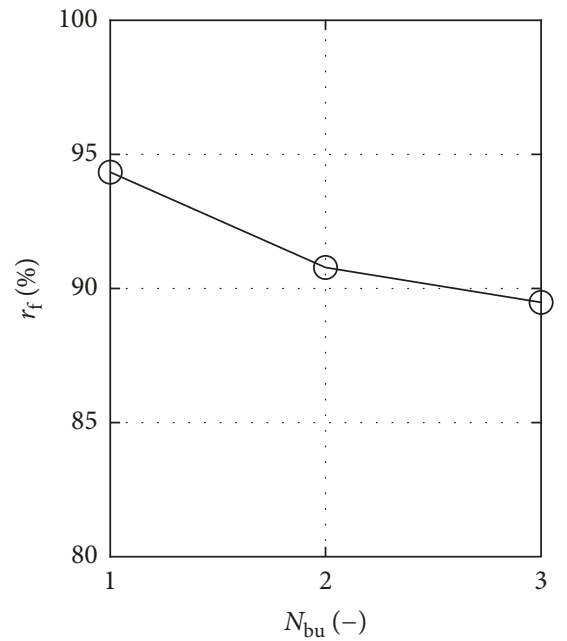

(c)

FIgURE 17: Impact force time histories on the bridge pier for the whole impact process (a), for the first $0.10 \mathrm{~s}$ of impact process (b) corresponding to different beam unit numbers, and the reduction ratio of maximum impact force versus beam unit number $N_{\text {bu }}$ (c). $\longrightarrow$, without the device; $\longrightarrow, N_{\text {bu }}=1 ;-, N_{\text {bu }}=2 ;-, N_{\text {bu }}=3$.

TABLE 2: Relationships of I cross-section dimensional parameters.

\begin{tabular}{lc}
\hline Ratio & Value $(-)$ \\
\hline$w_{\mathrm{bi}} / h_{\mathrm{bi}}$ & 1.0 \\
$t_{\mathrm{fi}} / h_{\mathrm{bi}}$ & 0.05 \\
$t_{\mathrm{wi}} / h_{\mathrm{bi}}$ & 0.03 \\
\hline
\end{tabular}

masses, that is, 181.4 ton (empty barge), 952.6 ton (half loaded barge), and 1723.7 ton (fully loaded barge), and three impact velocities, that is, $1.0 \mathrm{~m} / \mathrm{s}, 3.0 \mathrm{~m} / \mathrm{s}$, and $5.0 \mathrm{~m} / \mathrm{s}$, are considered herein. Each impact scenario is labeled as $\mathrm{IS}_{i j}$, where $i$ denotes the number index of barge mass varying from 1 to 3 and $j$ denotes the number index of impact velocity varying from 1 to 3 , as tabulated in Table 3 . The cap surface which contacts with the barge is flat and is $3.0 \mathrm{~m}$ in width. The cap mass $\left(m_{c}\right)$ is taken to be 100.0 ton. The number of planes of beam units $\left(N_{\mathrm{pl}}\right)$ is taken to be two. The yielding strength of beam steel $\left(f_{\mathrm{y}}^{\mathrm{bs}}\right)$ is taken to be 350.0 MPa, and the maximum allowable impact force $\left(F_{\max }^{\text {allow }}\right)$ on the bridge pier is taken to be $5.0 \mathrm{MN}$. The information of the prespecified parameters regarding the structure is tabulated in Table 4.

The optimum parameters generated by the proposed optimization model, the total masses of beam steel, and the configurations of optimum devices corresponding to different impact scenarios are tabulated in Table 5. The total number of beam units $\left(N_{\mathrm{bu}}^{\mathrm{total}}=N_{\mathrm{bu}} \times N_{\mathrm{pl}}\right)$ and the total mass of beam steel $\left(m_{\mathrm{sb}}\right)$ used by the optimum device plotted against total barge impact energy $\left(W_{\text {total }}\right)$ are shown in Figure 18, which shows that $N_{\text {bu }}^{\text {total }}$ increases to four, corresponding to two beam units in one plane, when $W_{\text {total }}$ reaches around 5.0 MNm. This is because the maximum cap displacement $\left(D_{\text {cap }}^{\max }\right)$ increases with the increase of $W_{\text {total }}$, as shown in Figure 19. When $W_{\text {total }}$ reaches around $5.0 \mathrm{MNm}, D_{\text {cap }}^{\max }$ increases to such a level that two beam units in one plane are needed to increase the maximum allowable cap displacement
TABLE 3: Impact scenarios considered for structure optimization.

\begin{tabular}{lcc}
\hline Impact scenario & $m_{\mathrm{b}}$ (ton) & $v_{\mathrm{b}}(\mathrm{m} / \mathrm{s})$ \\
\hline $\mathrm{IS}_{11}$ & 181.4 & 1.0 \\
$\mathrm{IS}_{12}$ & 181.4 & 3.0 \\
$\mathrm{IS}_{13}$ & 181.4 & 5.0 \\
$\mathrm{IS}_{21}$ & 952.6 & 1.0 \\
$\mathrm{IS}_{22}$ & 952.6 & 3.0 \\
$\mathrm{IS}_{23}$ & 952.6 & 5.0 \\
$\mathrm{IS}_{31}$ & 1723.7 & 1.0 \\
$\mathrm{IS}_{32}$ & 1723.7 & 3.0 \\
$\mathrm{IS}_{33}$ & 1723.7 & 5.0 \\
\hline
\end{tabular}

( $D_{\max }^{\text {allow }}$ ) based on (7), enabling $D_{\text {cap }}^{\max }$ to be lower than $D_{\max }^{\text {allow }}$ to satisfy the design requirement. It is also shown in Figure 18 that $m_{\mathrm{sb}}$ approximately shows linear dependency on $W_{\text {total }}$, indicating that $m_{\mathrm{sb}}$ is approximately directly proportional to barge mass while an increase of impact velocity could lead to a roughly quadratic increase of $m_{\mathrm{sb}}$.

The maximum cap displacements $\left(D_{\text {cap }}^{\max }\right)$ and maximum impact forces $\left(F_{\max }\right)$ on the pier corresponding to different impact scenarios are tabulated in Table 6, which shows that for each impact scenario, $D_{\text {cap }}^{\max }$ is smaller than $D_{\max }^{\text {allow }}$ and $F_{\max }$ is smaller than $F_{\max }^{\text {allow }}(5.0 \mathrm{MN})$; thus the design requirements can be satisfied for all impact scenarios. The maximum impact forces $\left(F_{\max }^{\text {unprot }}\right)$ on the pier for different impact scenarios without using the optimum devices are also tabulated in Table 6 along with the reduction ratio $\left(r_{f}\right)$ of maximum impact forces when the optimum devices are used. It is shown in Table 6 that the optimum device can significantly reduce the maximum impact force on the pier by more than $90.0 \%$ for different impact scenarios. Table 6 indicates that for a given impact velocity, $F_{\max }^{\text {unprot }}$ is not strongly influenced by barge mass. This phenomenon has been explained in detail in [8]. It is also indicated from Table 6 that $D_{\text {cap }}^{\max }$ is often close to or 
TABle 4: Prespecified parameters for structure optimization.

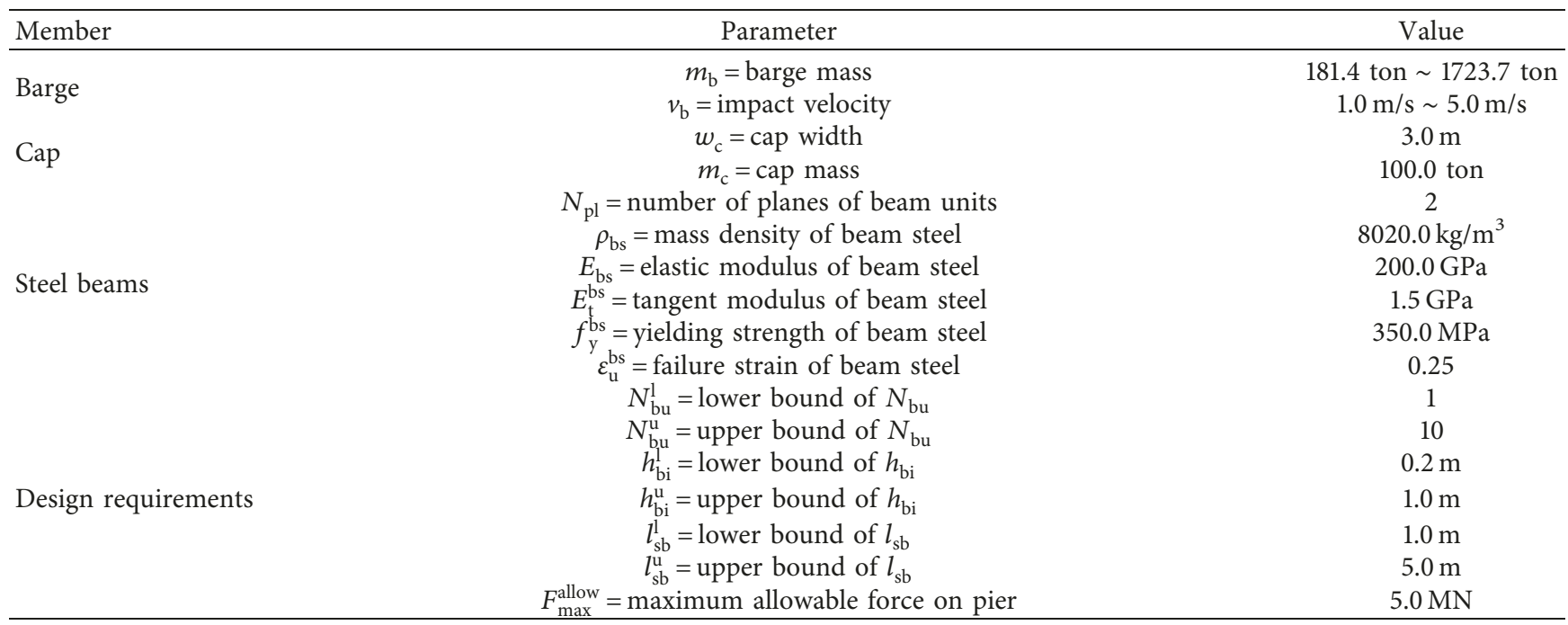

TABLE 5: Optimum parameters, total masses of beam steel, and configurations of optimum devices corresponding to different impact scenarios.

\begin{tabular}{|c|c|c|c|c|c|}
\hline $\begin{array}{l}\text { Impact } \\
\text { scenario }\end{array}$ & $N_{\text {bu }}(-)$ & $h_{\mathrm{bi}}(\mathrm{m})$ & $l_{\mathrm{sb}}(\mathrm{m})$ & $m_{\mathrm{sb}}($ ton $)$ & $\begin{array}{l}\text { Optimum structure } \\
\text { configuration }\end{array}$ \\
\hline $\mathrm{IS}_{11}$ & 1 & 0.20 & 1.00 & 0.41 & \\
\hline $\mathrm{IS}_{12}$ & 1 & 0.25 & 1.26 & 0.82 & \\
\hline $\mathrm{IS}_{13}$ & 1 & 0.35 & 1.76 & 2.22 & \\
\hline $\mathrm{IS}_{21}$ & 1 & 0.23 & 1.16 & 0.64 & \\
\hline IS $_{22}$ & 2 & 0.41 & 2.04 & 6.23 & \\
\hline $\mathrm{IS}_{23}$ & 2 & 0.57 & 2.83 & 16.62 & \\
\hline IS $_{31}$ & 1 & 0.29 & 1.43 & 1.19 & \\
\hline $\mathrm{IS}_{32}$ & 2 & 0.50 & 2.51 & 11.60 & \\
\hline $\mathrm{IS}_{33}$ & 2 & 0.70 & 3.48 & 30.77 & \\
\hline
\end{tabular}

equal to $D_{\max }^{\text {allow }}$. This is because for a given impact scenario, decreasing the amount of beam steel would reduce the structure stiffness and consequently lead to the increase of $D_{\text {cap }}^{\max }$ until the point where $D_{\text {cap }}^{\max }$ approximately reaches $D_{\max }^{\text {allow }}$ and the optimum solution is attained.

The maximum bending moment diagrams and deflections of the optimum devices corresponding to impact scenarios $\mathrm{IS}_{31}, \mathrm{IS}_{32}$, and $\mathrm{IS}_{33}$ are shown in Figure 20, which shows that the horizontal beams at the top and two vertical beams in the middle experience apparent plastic deformations after impact, enabling the devices to absorb high energy during impact, as shown in Figure 21.

\section{Summary}

This paper devised a novel crashworthy device for pier protection from barge impact and conducted parametric studies to investigate the effectiveness of the proposed device using the simplified impact model. A mathematical optimization model was developed with constraints as per the prescribed design requirements to achieve costoptimized design of the device for a given impact scenario.

The studies indicate that the proposed crashworthy device has a large energy dissipation capacity due to the 


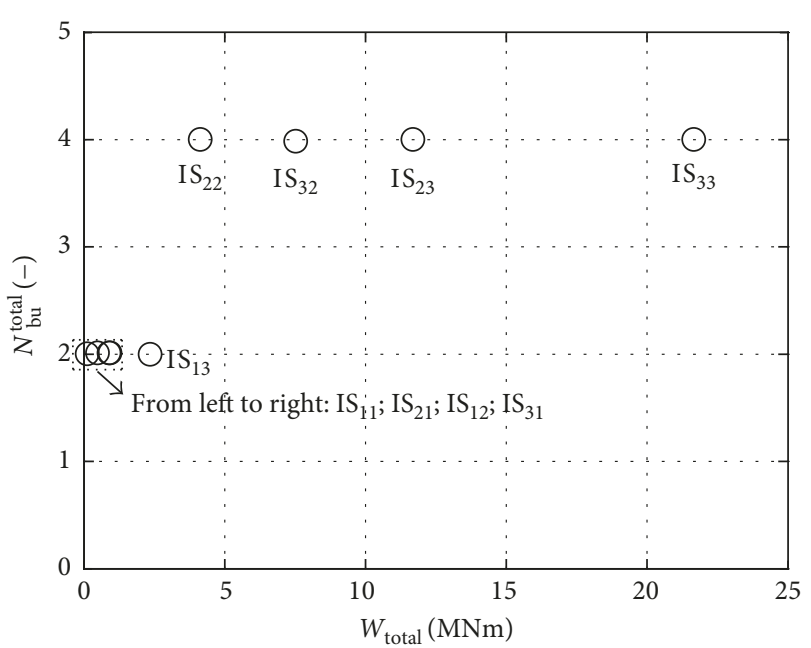

(a)

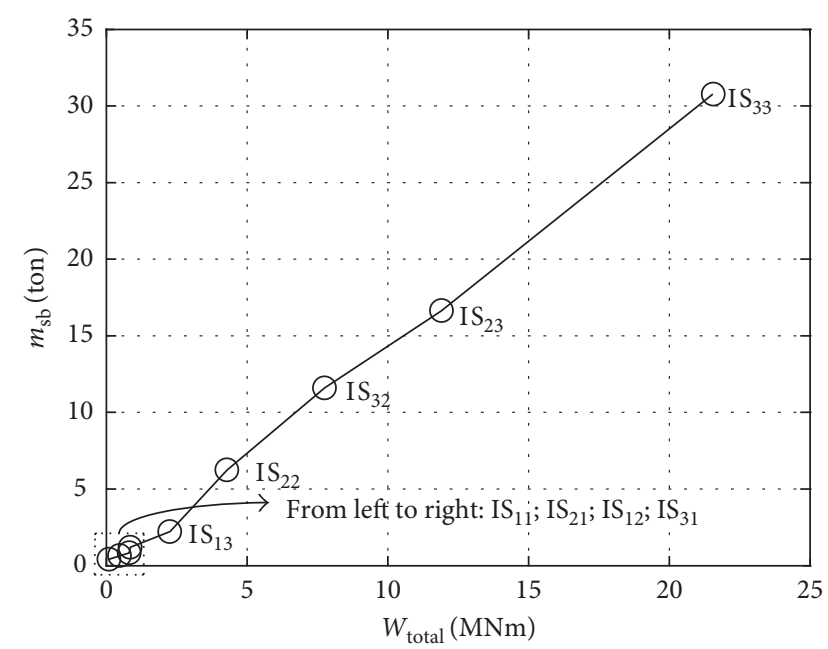

(b)

FIGURE 18: The total number of beam units $N_{\mathrm{bu}}^{\text {total }}$ and the total mass of beam steel $m_{\mathrm{sb}}$ used by the optimum device versus barge impact energy $W_{\text {total }}\left(N_{\mathrm{pl}}=2\right)$.

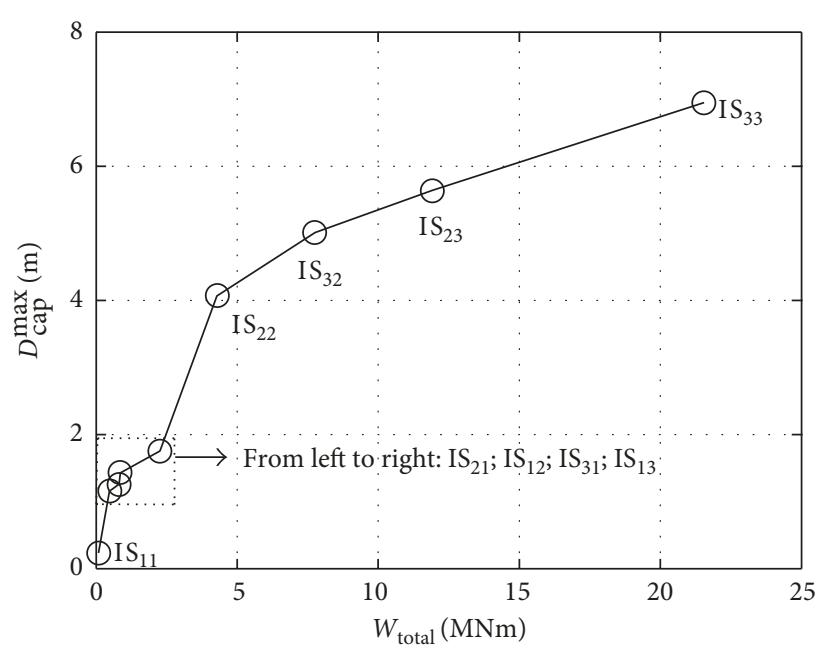

(a)

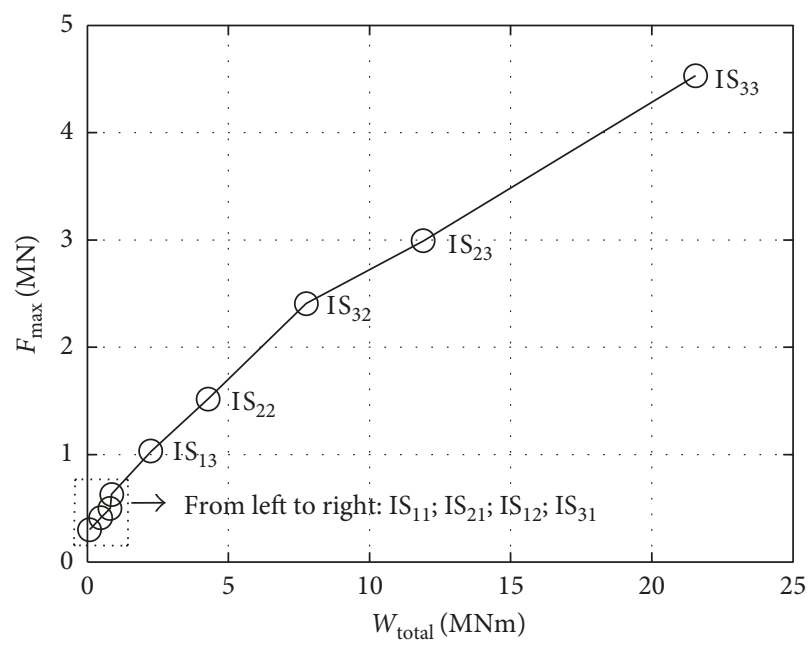

(b)

Figure 19: Maximum cap displacement $D_{\text {cap }}^{\max }$ (a) and maximum impact force on the bridge pier $F_{\text {max }}(\mathrm{b})$ versus barge impact energy $W_{\text {total }}$ using the optimum device.

TABLE 6: Maximum cap displacements and maximum impact forces on the pier using or without using optimum devices corresponding to different impact scenarios.

\begin{tabular}{lccccc}
\hline Impact scenario & $D_{\text {cap }}^{\max }(\mathrm{m})$ & $D_{\max }^{\text {allow }}(\mathrm{m})$ & $F_{\max }(\mathrm{MN})$ & $F_{\max }^{\text {unprot }}(\mathrm{MN})$ & $r_{\mathrm{f}}=100 \times\left(F_{\max }^{\text {unprot }}-F_{\max }\right) / F_{\max }^{\text {unprot }}(\%)$ \\
\hline $\mathrm{IS}_{11}$ & 0.23 & 1.00 & 0.30 & 16.24 & 98.15 \\
$\mathrm{IS}_{12}$ & 1.26 & 1.26 & 0.50 & 39.90 & 98.75 \\
$\mathrm{IS}_{13}$ & 1.75 & 1.76 & 1.03 & 47.57 & 97.83 \\
$\mathrm{IS}_{21}$ & 1.16 & 1.16 & 0.41 & 27.24 & 98.50 \\
$\mathrm{IS}_{22}$ & 4.07 & 4.08 & 1.52 & 39.68 & 96.17 \\
$\mathrm{IS}_{23}$ & 5.64 & 5.66 & 2.99 & 48.53 & 93.84 \\
$\mathrm{IS}_{31}$ & 1.43 & 1.43 & 0.63 & 27.18 & 97.68 \\
$\mathrm{IS}_{32}$ & 5.01 & 5.02 & 2.41 & 39.45 & 93.89 \\
$\mathrm{IS}_{33}$ & 6.95 & 6.95 & 4.56 & 48.63 & 90.62 \\
\hline
\end{tabular}




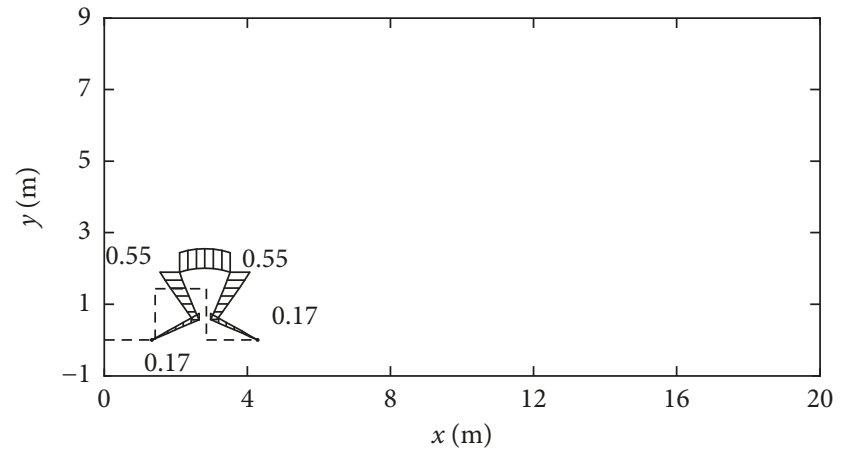

(a)

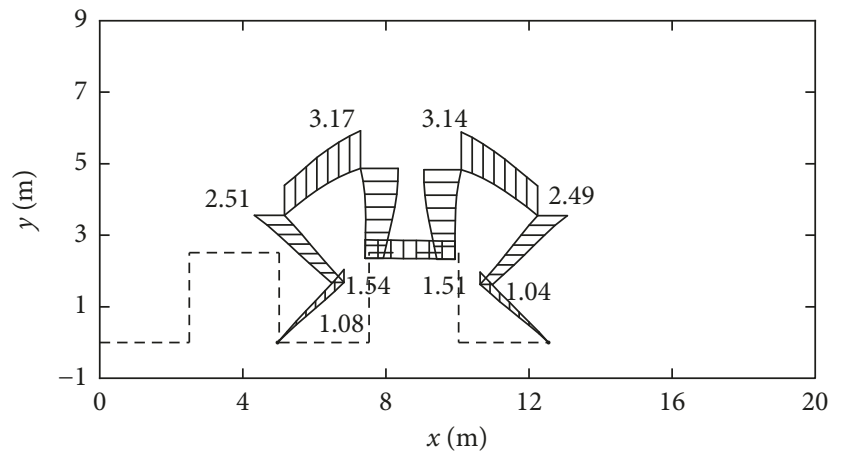

(b)

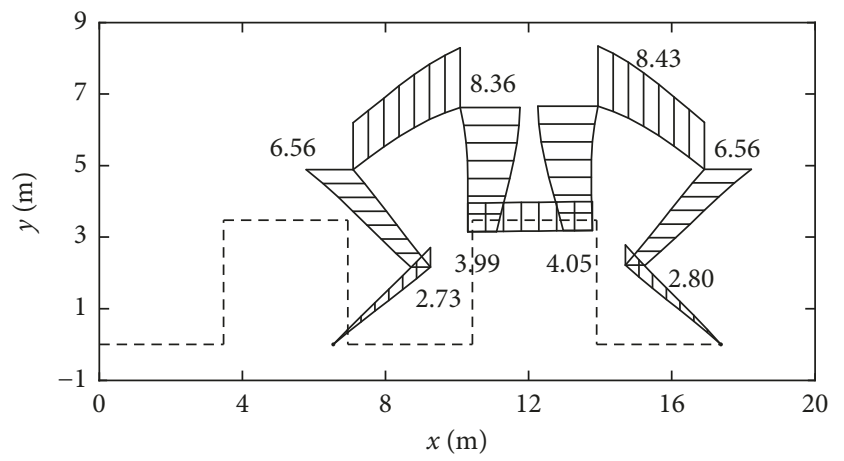

(c)

FIGURE 20: Maximum bending moment diagrams of the optimum devices during impact and deflections of the structures after the impact corresponding to the impact scenarios (a) IS $_{31}$, (b) IS $_{32}$, and (c) $\mathrm{IS}_{33}$ (unit: $\mathrm{MNm}$ ). - - original shape of the device; deformed shape of the device.

formation of plastic hinges in the structure during impact. These number and location of plastic hinges, and consequently the energy that can be absorbed, is determined by the design of the frame-like steel beam arrangement. The studies show that the magnitude of the impact force transmitted to the main bridge pier can be dramatically reduced when the device is properly designed and installed and that the maximum force transmitted can be chosen as part of the device design. A mathematical optimization model proposed in this paper can be used for obtaining the optimum

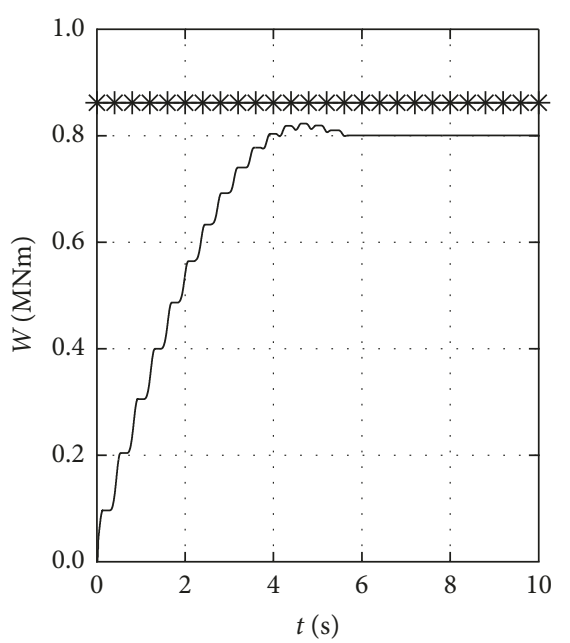

(a)

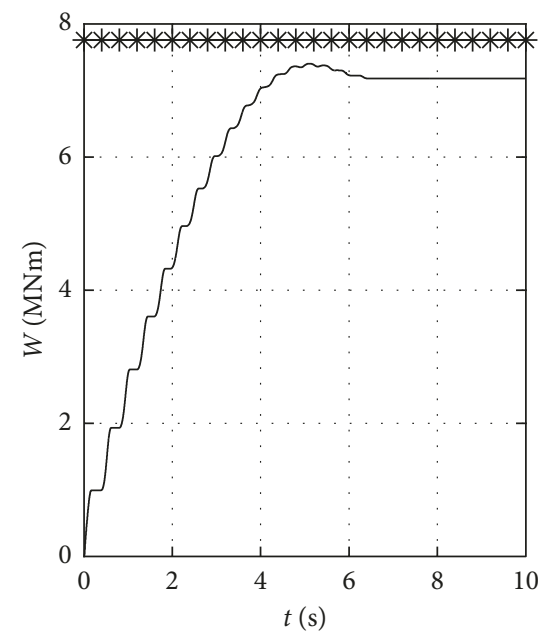

(b)

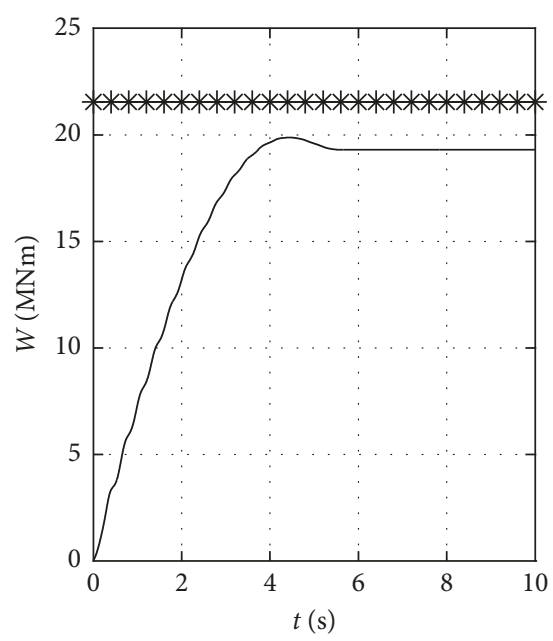

(c)

FIgURE 21: Energy absorbed by the optimum device (- - ) and the total impact energy (-*-) during impact corresponding to the impact scenarios (a) $\mathrm{IS}_{31}$, (b) $\mathrm{IS}_{32}$, and (c) $\mathrm{IS}_{33}$. 
configuration of the device which satisfies the design requirements for a given impact scenario.

The concept proposed here can be extended further to other configurations, for example, symmetrical or entwined arrangements which avoid vertical displacements or reduce the device's overall dimensions, respectively.

The device concept presented and the analysis model adopted have the potential to rationalize ship impact protection and thus to provide cost-effective future protection solutions.

\section{Conflicts of Interest}

The authors declare that there are no conflicts of interest regarding the publication of this paper.

\section{Acknowledgments}

The authors wish to thank the China Scholarship Council for providing scholarship to W. Wang for conducting the study.

\section{References}

[1] S. E. Manen and A. G. Frandsen, "Ship collision with bridges, review of accidents," in Ship Collision Analysis, H. Gluver and D. Olsen, Eds., pp. 3-11, Balkema, Rotterdam, Netherlands, 1998.

[2] O. D. Larsen, Ship Collision with Bridges, the Interaction between Vessel Traffic and Bridge Structures, IABSE, Zuerich, Switzerland, 1993.

[3] P. Yuan, Modeling, Simulation, and Analysis of Multi-Barge Flotillas Impacting Bridge Piers, Ph.D. thesis, Department of Civil Engineering, University of Kentucky, Lexington, Kentucky, 2005.

[4] C. H. Cao, Simplified Static and Dynamic Analysis for BargeBridge Collision, M.S. thesis, Department of Bridge Engineering, Tongji University, Shanghai, China, 2010, in Chinese.

[5] Y. Y. Sha and H. Hao, "Laboratory tests and numerical simulations of barge impact on circular reinforced concrete piers," Engineering Structures, vol. 46, pp. 593-605, 2013.

[6] Y. Y. Sha and H. Hao, "Laboratory tests and numerical simulations of CFRP strengthened RC pier subjected to barge impact load," International Journal of Structural Stability and Dynamics, vol. 15, no. 2, p. 1450037, 2015.

[7] Y. Y. Sha and H. Hao, "Nonlinear finite element analysis of barge collision with a single bridge pier," Engineering Structures, vol. 41, pp. 63-76, 2012.

[8] W. Wang and G. Morgenthal, "Dynamic analyses of square RC pier column subjected to barge impact using efficient models," Engineering Structures, vol. 151, pp. 20-32, 2017.

[9] R. Saul, K. Humpf, and A. Patsch, "The Rosario-Victoria cable-stayed bridge across the river Paran $\tilde{A}_{i}$ in Argentina and its ship impact protection system," in Proceedings of the First International Conference on Steel and Composite Structures, pp. 1011-1018, Pusan, South Korea, June 2001.

[10] G. Morgenthal and R. Saul, "Die Geh- und Radwegbruecke Kehl-Strasbourg," Stahlbau, vol. 74, no. 2, pp. 121-125, 2005, in German.
[11] M. Knott, "Pier protection system for the sunshine skyway bridge replacement," in Proceedings at 3rd Annual International Bridge, pp. 56-61, Pittsburghn, PA, USA, 1986.

[12] B. C. Simonsen and N. Ottesen-Hansen, "Protection of marine structures by artificial islands," in Proceedings of the International Symposium on Advances in Ship Collision Analysis, Balkema Publishers, pp. 201-215, Copenhagen, Denmark, May 1998.

[13] H. Svensson, "Protection of bridge piers against ship collision," Steel Construction, vol. 2, no. 1, pp. 21-32, 2009.

[14] R. Pinzelli and K. Chang, "Reinforcement of bridge piers with FRP sheets to resist vehicle impact: tests on large concrete columns reinforced with aramid sheets," in Proceedings of the International Conference on FRP Composites in Civil Engineering, pp. 12-15, Hong Kong, China, December 2001.

[15] T. N. Le, J. M. Battini, and M. Hjiaj, "Corotational dynamic formulation for 2d beams," in ECCOMAS Thematic Conference on Computational Methods in Structural Dynamics and Earthquake Engineering, Corfu, Greece, May 2011.

[16] W. Hock and K. Schittkowski, "A comparative performance evaluation of 27 nonlinear programming codes," Computing, vol. 30, no. 4, pp. 335-358, 1983. 


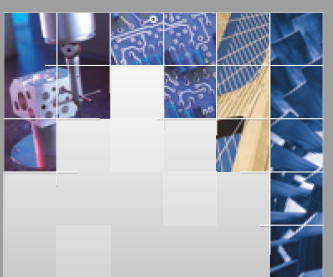

\section{Enfincering}
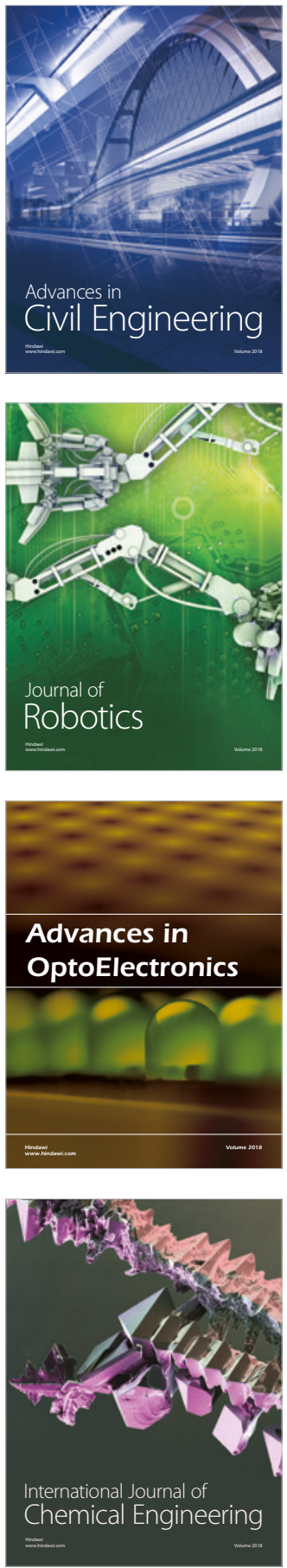

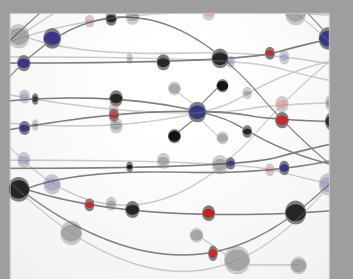

\section{Rotating \\ Machinery}

The Scientific World Journal

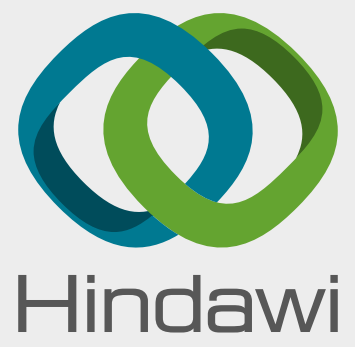

Submit your manuscripts at

www.hindawi.com
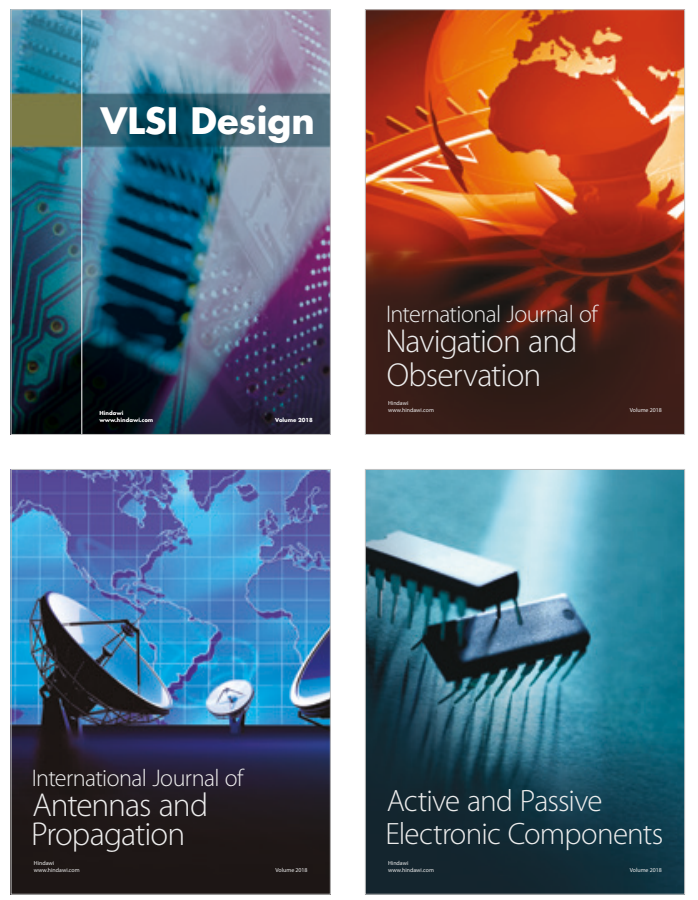
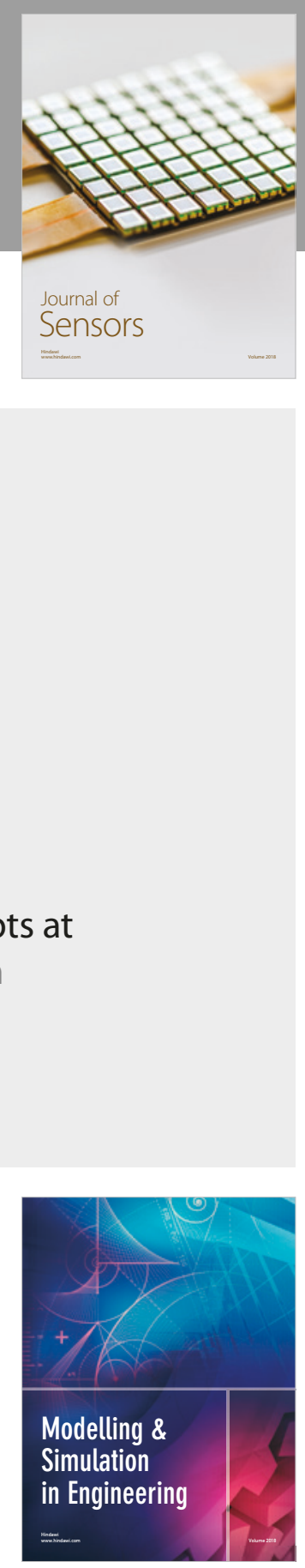

\section{Advances \\ Multimedia}
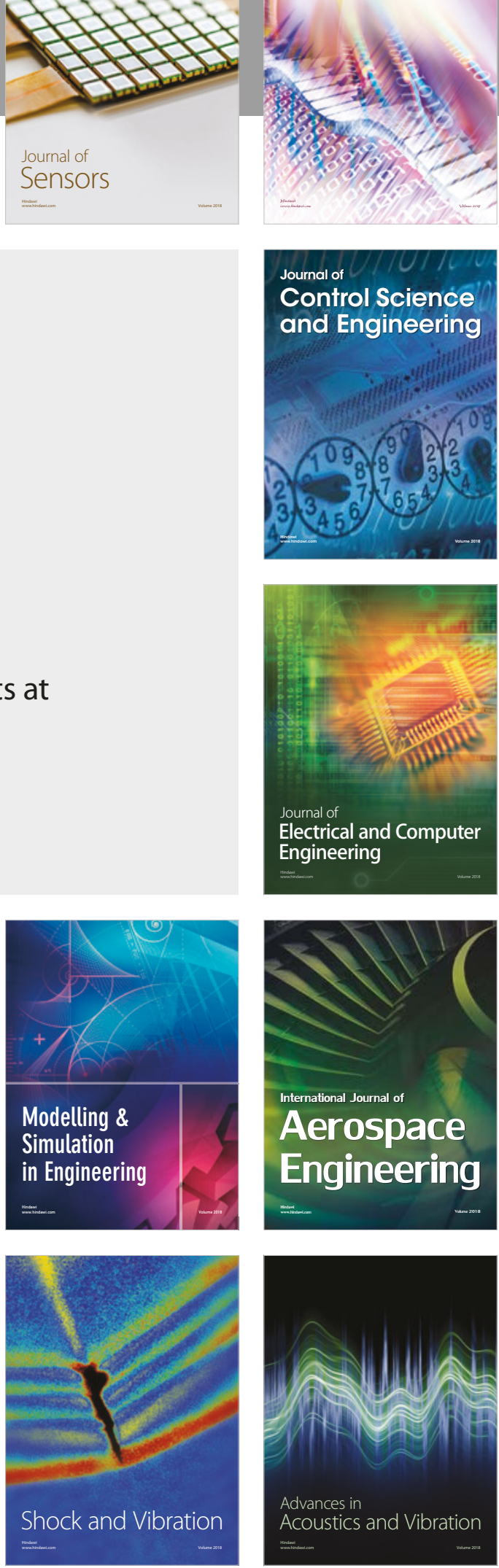